\title{
The term structure of bond market liquidity conditional on the economic environment: an analysis of government guaranteed bonds
}

by Philipp Schuster and Marliese

Uhrig-Homburg

No. 45 | NOVEMBER 2012

\section{WORKING PAPER SERIES IN ECONOMICS}

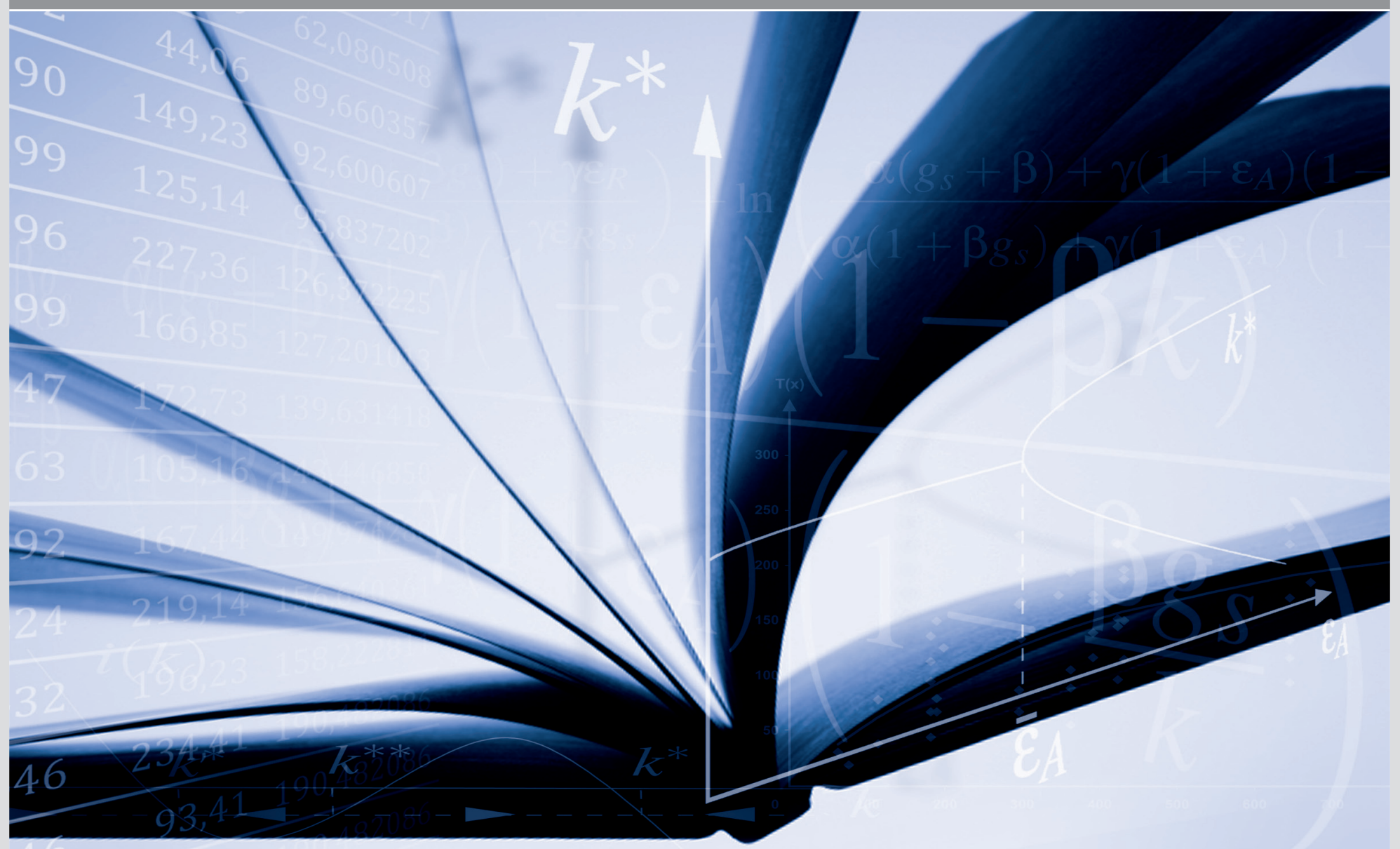




\section{Impressum}

Karlsruher Institut für Technologie (KIT)

Fakultät für Wirtschaftswissenschaften

Institut für Wirtschaftspolitik und Wirtschaftsforschung (IWW)

Institut für Wirtschaftstheorie und Statistik (ETS)

Schlossbezirk 12

76131 Karlsruhe

KIT - Universität des Landes Baden-Württemberg und nationales Forschungszentrum in der Helmholtz-Gemeinschaft

Working Paper Series in Economics

No. 45, November 2012

ISSN 2190-9806

econpapers.wiwi.kit.edu 


\title{
The Term Structure of Bond Market Liquidity Conditional on the Economic Environment:
}

\section{An Analysis of Government Guaranteed Bonds ${ }^{\dagger}$}

\author{
Philipp Schuster* and Marliese Uhrig-Homburg**
}

Current Version: October 2012

JEL Classification: G01, G11, G12, G13

Keywords: bond liquidity, term structure of illiquidity premiums, regime-switching, financial crisis, flight-to-liquidity

\footnotetext{
${ }^{\dagger}$ We thank seminar participants at the workshop Financial Markets \& Risk 2010 (University Innsbruck), a workshop at Deutsche Bundesbank in September 2011, the DGF PhD Workshop 2011, the Colloquium on Financial Markets in Cologne 2012, SGF 2012, DGF 2012, as well as Ralf Elsas, Rüdiger Fahlenbrach, Roland Füss, Alexander Kempf, Olaf Korn, Paulo Maio, Stefan Ruenzi, Christian Schlag, Claus Schmitt, Erik Theissen, Maxim Ulrich, Nils Unger, and Josef Zechner for helpful comments and suggestions.

*Philipp Schuster, Chair of Financial Engineering and Derivatives, Karlsruhe Institute of Technology (KIT), P.O. Box 6980, D-76049 Karlsruhe, Germany, Phone +49 721608 48184, Fax +49 72160848190 , Email philipp.schuster@kit.edu

${ }^{* *}$ Prof. Dr. Marliese Uhrig-Homburg, Chair of Financial Engineering and Derivatives, Karlsruhe Institute of Technology (KIT), P.O. Box 6980, D-76049 Karlsruhe, Germany, Phone +49 721608 48183, Fax +49721608 48190, Email uhrig@kit.edu.
} 


\title{
The Term Structure of Bond Market Liquidity Conditional on the Economic Environment:
}

\author{
An Analysis of Government Guaranteed Bonds
}

\begin{abstract}
We analyze the term structure of illiquidity premiums as the difference between the yield curves of two major bond segments that are both government guaranteed but differ in their liquidity. We show that its characteristics strongly depend on the economic situation. In crisis times, illiquidity premiums are higher with the largest increase for short-term maturities. Moreover, their reaction to changes in fundamentals is only significant during crises: premiums of all maturities depend on inventory risk, short maturities are highly sensitive to liquidity preferences (flight-to-liquidity). Therefore, calibrating risk management models in normal times underestimates illiquidity risk and misjudges term structure effects.
\end{abstract}

JEL Classification: G01, G11, G12, G13

Keywords: bond liquidity, term structure of illiquidity premiums, regime-switching, financial crisis, flight-to-liquidity 


\section{Introduction}

It is consensus in the literature that a large part of the yield spread compensates investors for the illiquidity of a bond (see e.g., Longstaff, Mithal, and Neis, 2005). However there remain a number of important questions. Do illiquidity premiums behave substantially differently in different economic periods? Or are they driven by the same economic determinants independent of the economic environment? To what extent do such drivers affect different parts of the term structure of illiquidity premiums in a different manner? A deep understanding of the characteristics of illiquidity premiums is of key importance given both the enormous and rapidly increasing size of bond markets and their role in the economy as a major source of financing.

The majority of empirical studies of illiquidity premiums in bond markets analyze average effects both with respect to the economic environment and the bonds' maturity. Thus, they are silent on the above issues. To the best of our knowledge no previous study analyzes the term structure of illiquidity premiums conditional on the economic environment. We examine behavior and determinants of illiquidity premiums for different maturities and allow explicitly for a regime dependent behavior. This distinguishes our paper from the rest of the literature. Moreover, in contrast to our paper, many studies suffer from the problem that empirically disentangling risk premiums due to illiquidity from other systematic factors such as default risk is a tedious task and often subject to strong assumptions.

Given the close link between liquidity and credit risk, an ideal setting would be to study the differences between zero coupon yield curves of two bond segments fulfilling three requirements: First, both segments only differ in their liquidity. Second, in each segment, there are a sufficient number of bonds available over a long observation period. Third, the bonds in each segment are completely homogeneous. 
German government bonds (BUNDs) and government guaranteed bonds issued by the German federal agency Kreditanstalt für Wiederaufbau (KfW) provide a near-ideal setting. They constitute major bond market segments in the eurozone with a sufficient number of bonds from both issuers in all maturity segments. Since KfW bonds are explicitly guaranteed by the German government, they bear effectively the same default risk as government bonds. However, they are clearly less liquid. This clean environment allows us to isolate the term structures of illiquidity premiums. Moreover, we can study their drivers conditional on the state of the economy based on 15 years of data from 1996 to 2010. In order to contribute to a more comprehensive understanding of the nature of illiquidity premiums, we study their term structures with Hamilton's regime-switching approach.

Three main results emerge from the analysis. First, the regime-switching approach applied on an autoregressive model of illiquidity premiums of different maturities identifies the 1998 bailout of Long Term Capital Management (LTCM), the period after the burst of the dot-com bubble as well as the financial crisis starting in summer 2007 as liquidity stress periods in the European bond market.

Second, we find that the term structure of illiquidity premiums varies over time and is strongly dependent on the general financial and economic situation. In normal times, the average illiquidity premium measured as the extra yield to maturity of an illiquid agency bond compared to a liquid government bond is around 15 bps. This premium nearly doubles in times of stress for all maturity segments but the increase is most prevalent at the short end. Thus, term structures of illiquidity premiums in times of crisis are often strongly downward sloping as predicted by theoretical models when probabilities to sell are above their long-term mean (see Ericsson and Renault, 2006) or when aggregate liquidity shocks are more likely (see Feldhütter, 2012).

Third, we find that none of our economic drivers plays a major role in explaining premiums in normal times. In contrast, factors accounting for the degree of bond illiquidity and 
factors accounting for preferences for liquidity are important in periods of stress. While option-implied interest rate volatilities which proxy for the degree of illiquidity have significant explanatory power for all maturity segments, preferences for liquidity drive the short end only. This finding is consistent with the clearly higher short-term premiums and can be explained with flight-to-liquidity periods that coincide with stress periods. An increased demand for short-term and highly liquid securities within these periods leads first to a strongly increased level of illiquidity premiums and second to a stronger influence of effects stemming from liquidity demand. If we estimated our model unconditionally, statistical significances would be the same as for the crisis regime, but economic significances would be weak. Thus, an unconditional estimation would both misjudge economic drivers and contradict theoretical models predicting a close connection between systematic factors and illiquidity premiums (see e.g., Acharya and Pedersen, 2005). Our regime-switching approach therefore helps to reconcile theory and empirical findings.

Overall, the regime-switching nature of the term structure of illiquidity premiums documented in this study goes well together with the theoretical insights of Brunnermeier and Pedersen (2009) that the impact of changes in fundamentals on illiquidity is significantly stronger when funding is scarce and the system is in stress. This implies that calibrating e.g., risk management models in normal times, where illiquidity premiums are largely invariant to changes in fundamentals, heavily underestimates the systematic component of liquidity risk. Moreover, preferences for liquidity appear only in short-term premiums making it worthwhile to incorporate term structure effects.

Despite the importance of these relations, empirical research in this area has been limited. Empirical evidence that liquidity effects in bond markets are conditional on the state of the economy includes the important papers of Brunnermeier (2009), Dick-Nielsen, Feldhütter, and Lando (2012), and Acharya, Amihud, and Bharath (2010). While Brunnermeier (2009) and Dick-Nielsen, Feldhütter, and Lando (2012) clearly document a different behavior of liquidity during crisis and non-crisis times, Acharya, Amihud, and Bharath (2010) explicitly identify two liquidity regimes and document the regime-dependent im- 
portance of liquidity betas. Given their focus on corporate bonds, all these studies suffer from the separation between liquidity and credit risk. Moreover, the term structure of illiquidity premiums is outside the scope of these papers.

Some recent research focuses on the term structure of illiquidity premiums. Longstaff (2004) studies yield differences between Treasuries and Refcorp bonds. He finds a positive influence of changes in the amount of funds held in money market mutual funds on short-term illiquidity premiums, whereas medium-term premiums increase when consumer confidence declines. Both effects can be interpreted in the way that an increased wariness to bear risk increases the premium of holding an illiquid bond. Kempf, Korn, and Uhrig-Homburg (2012) estimate the term structure of illiquidity premiums for German Pfandbriefe. They find a positive influence of short- and long-term liquidation needs on the respective illiquidity premiums, the former proxied by asset market volatilities, the latter directly linked to a deteriorating economic outlook. Both studies do not pursue a conditional approach, rather they analyze 'average' effects over the whole business cycle. Finally, Goyenko, Subrahmanyam, and Ukhov (2011) study the term structure of Treasury market illiquidity. Although their focus is on bond market trading cost measured via bidask spreads instead of yield differentials, their findings of increasing illiquidity in recessions across all maturities with the increase being especially pronounced for short-term bonds is pretty much consistent with our insights on the premium side.

The remainder of the paper is structured as follows: Section 2 provides details on how we extract the term structure of illiquidity premiums. In Section 3, we study the term structure of illiquidity premiums in a regime-switching model and analyze economic determinants of illiquidity premiums of different maturities conditional on the economic environment. Section 4 performs several robustness checks. Section 5 concludes the paper. 


\section{Illiquidity Premiums}

We extract the illiquidity premium by estimating the zero coupon yield curves of two bond market segments that differ only in their liquidity: highly liquid BUNDs and more illiquid bonds guaranteed by the German government but issued by the German federal agency KfW. The interpretation of the KfW-BUND bond yield spread curve as the term structure of illiquidity premiums depends on two key assumptions: that federal agency bonds are less liquid than government bonds and that credit risk in both segments is exactly the same. We describe first our data set, the approach to extract the term structure of illiquidity premiums, and the resulting shapes of illiquidity premiums and then provide support that the KfW-BUND spread can indeed be attributed to liquidity differences.

\subsection{DATA, TERM STRUCTURE ESTIMATION, AND EVOLUTION OF PREMIUMS}

Our data set consists of weekly closing prices for BUNDs and KfW bonds from the Frankfurt Stock exchange from February 14th, 1996 to September 29th, 2010. During this period, there are always a sufficient number of bonds from both issuers in all maturity segments available. We only include those KfW bonds that are well comparable to BUNDs: plain vanilla fixed coupon bonds with annual coupon payments that are exchange-tradable and denominated in Euro. Table I gives an overview of all bonds in our sample.

\section{[Insert Table I about here.]}

We estimate the term structure of zero coupon yields of BUNDs and KfW bonds using the Nelson and Siegel (1987) approach. Within this approach, the entire term structure information at time $t$ is condensed in four parameters $\left(\beta_{0, t}, \beta_{1, t}, \beta_{2, t}, \tau_{t}\right)$. The zero coupon yield of bond class $i \in\{B U N D, K f W\}$ at time $t$ for time to maturity $T$ is given as

$$
y_{t}^{i}(T)=\beta_{0, t}^{i}+\beta_{1, t}^{i}\left(\frac{1-e^{-\frac{T}{\tau_{t}^{i}}}}{\frac{T}{\tau_{t}^{i}}}\right)+\beta_{2, t}^{i}\left(\frac{1-e^{-\frac{T}{\tau_{t}^{i}}}}{\frac{T}{\tau_{t}^{i}}}-e^{-\frac{T}{\tau_{t}^{i}}}\right) .
$$


To make the $\beta$-factors of both BUNDs and KfWs directly comparable and to restrict the shape of the term structure of illiquidity premiums to shapes allowed within the NelsonSiegel approach, we further impose $\tau_{t}^{B U N D}=\tau_{t}^{K f W}=\tau_{t}$ (see also Nelson and Siegel, 1987 and Diebold and Li, 2006 who restrict $\tau$ to be constant over time $t$ ).

Estimation of the parameter vector $\omega_{t}=\left(\beta_{0, t}^{B U N D}, \beta_{1, t}^{B U N D}, \beta_{2, t}^{B U N D}, \beta_{0, t}^{K f W}, \beta_{1, t}^{K f W}, \beta_{2, t}^{K f W}, \tau_{t}\right)$ is carried out for each week $t$ separately by standard OLS techniques: We minimize the sum of squared differences between observed and theoretical Nelson-Siegel yields for all bonds in both segments by

$\min _{\omega_{t}} \frac{1}{N_{t}^{B U N D}} \sum_{j=1}^{N_{t}^{B U N D}}\left(y l d_{j, t}^{o b s, B U N D}-y l d_{j, t}^{t h, B U N D}\right)^{2}+\frac{1}{N_{t}^{K f W}} \sum_{k=1}^{N_{t}^{K f W}}\left(y l d_{k, t}^{o b s, K f W}-y l d_{k, t}^{t h, K f W}\right)^{2}$

where the theoretical yield $y l d_{j, t}^{t h, i}$ of bond $j$ from bond class $i$ is obtained by discounting all its future cash flows with $y_{t}^{i}(T)$. To put equal weights on both segments for the estimation of the common $\tau_{t}$, we weight the sum of squared yield differences with the inverse of the number of bonds $N_{t}^{i}$ in the respective bond class. As in Schich (1997), who developed the estimation procedure for the benchmark yield curve employed by the German central bank, we exclude bonds with time to maturity less than three months since for them small errors in the price would translate to large yield errors. Fitting errors are presented in Table II. Root mean square errors (RMSE) are in the same order of magnitude for all maturities and both segments and there is no systematic bias of yield curve estimates.

[Insert Table II about here.]

The term structure of illiquidity premiums at time $t$ is then obtained as the difference between the two estimated Nelson-Siegel curves

$$
i l i q_{t}(T)=y_{t}^{K f W}(T)-y_{t}^{B U N D}(T)
$$


To get a first impression on different shapes of the term structure, Figure 1 shows the evolution of the two, five, and eight year illiquidity premiums. There are clearly different forms over time. So for example from mid 2000 until mid 2001, an increasing term structure can be observed, whereas the end of 2006 and the beginning of 2007 are characterized by U-shaped term structures. After the collapse of Lehman Brothers, the term structure becomes strongly decreasing. On average, the term structure of illiquidity premiums is slightly U-shaped with premiums of 21.6 bps for two years, 17.9 bps for five years, and 18.3 bps for eight years time to maturity.

\section{[Insert Figure 1 about here.]}

Average illiquidity premiums are similar in magnitude to the 9 to 40 bps range found in previous studies of US and European bond market liquidity. ${ }^{1}$ Regarding the shape of the term structure, Amihud and Mendelson (1991) find a declining one for US Treasury notes compared to more liquid Treasury bills in 1987, whereas Longstaff (2004) presents evidence for a U-shaped, and Koziol and Sauerbier (2007) for a hump-shaped profile. ${ }^{2}$ Our findings help to reconcile these conflicting outcomes as the shape of the term structure of illiquidity premiums depends on the general financial and economic situation. In contrast to Kempf, Korn, and Uhrig-Homburg (2012) who also observe varying forms for the Pfandbrief segment, our homogeneous data set of bonds from only two issuers allows us to rule out unobserved changing intra-segment liquidity differences as a possible explanation.

\footnotetext{
${ }^{1}$ Longstaff (2004) finds an illiquidity premium of 9 to 16 bps for zero coupon strips derived from six long-term Refcorp bonds for the period 1991 to 2001 and Koziol and Sauerbier (2007) find on average 20.4 bps for German Jumbo Pfandbriefe for the years 2000 to 2001. Kempf, Korn, and Uhrig-Homburg (2012) report an average illiquidity premium between 29 bps for one year and 40 bps for 15 years of time to maturity for the relatively heterogeneous segment of German Pfandbriefe from 2000 to 2007.

${ }^{2}$ Liu, Longstaff, and Mandell (2006) and de Jong and Driessen (2006) filter premiums for illiquidity risk out of swap and corporate bond spreads. Dick-Nielsen, Feldhütter, and Lando (2012) estimate a liquidity component as a fraction of corporate bond spreads. All three papers find an increasing term structure.
} 


\subsection{THE KFW-BUND YIELD SPREAD AND LIQUIDITY MEASURES}

In this section, we argue that both KfW bonds and BUNDs are virtually identical in all relevant characteristics except their liquidity. We show that KfW bonds are less liquid than corresponding government bonds and present time-series relations between illiquidity premiums and liquidity measures. Thus, the KfW-BUND spread can be attributed to liquidity differences (see also Schwarz, 2010; Monfort and Renne, 2010).

KfW is a promotional bank owned by the German government and federal states. It was founded in 1948 to further the reconstruction of the German economy after World War II. Today, it serves as the leading financier of small and medium size enterprises, provides credit to retail customers for subsidized projects (e.g., improving energy efficiency of buildings), and acts on behalf of the German government on special tasks. All KfW bonds are guaranteed by the German government and thus bear effectively the same default risk as government bonds. This is recognized e.g., by the US economic magazine 'Global Finance' honoring KfW as the world's safest bank in 2009, 2010, and 2011. Besides their identical credit risk, KfWs and BUNDs are zero weighted in determining capital requirements within the Basel regulations, and are also identical in their tax treatment. In contrast, the two segments differ in their liquidity due to the about eleven times higher outstanding total volume and the more than three times higher average issue size of BUNDs compared to KfW bonds (see Table I). Note also that although KfWs and BUNDs are both accepted by the European Central Bank (ECB) as collateral for repo transactions, ECB divides securities in liquidity categories. KfWs are in the second highest category, whereas BUNDs are in the highest. ${ }^{3}$

\footnotetext{
${ }^{3}$ This leads to small additional haircuts for KfWs of up to $2 \%$ for the longest maturities. KfWs and BUNDs are both accepted by the Federal Reserve for discount window loans with the same margin haircuts. The Bank of England accepts KfWs only as 'wider collateral' which can be used for long-term open market operations and the discount window facility, whereas BUNDs are accepted for all monetary policy operations.
} 
To provide further support that illiquidity premiums are driven by liquidity differences between the two segments, we analyze the time-series relation between illiquidity premiums and corresponding liquidity measures for three maturity segments in more detail. We obtain relative bid-ask spreads from all contributors providing quotations in Bloomberg and compute the average bid-ask spread for each bond and each date. To calculate a time to maturity dependent measure, we estimate a linear relation between the duration of the bond and the bid-ask spread for each segment and each date. With the estimated 'term structure of bid-ask spreads' we are able to aggregate the information from all bonds of a segment in maturity dependent bid-ask spreads similarly as for the estimation of the term structure of illiquidity premiums. Bid-ask quotations are available only since 1999 for a majority of KfW bonds, two-sided quotes for bonds of durations less than two years are only available after August 22nd, 2001 on a continuous basis.

Figure 2 presents the evolution of the two, five, and eight year illiquidity premiums over time together with the respective quoted bid-ask spread differences. For all three maturity segments, the figure shows a remarkable connection between bid-ask spread differences and illiquidity premiums. Their unconditional correlation is 0.89 for two years, 0.85 for five, and 0.84 for eight years maturity. These findings provide clear and consistent evidence in favor of liquidity-driven yield spreads.

[Insert Figure 2 about here.]

To further rule out the possibility that the KfW-BUND yield spread is due to a convenience yield for BUNDs, we compare the average illiquidity premium with the spread between the general collateral repo rate (EUREPO) and BUND. In the time period for which EUREPO is available (since March 2002), the average difference between the day count adjusted EUREPO twelve months and the one year BUND rate is with 8.5 bps less than one fourth of the average one year illiquidity premium during this time period of 36.8 bps. Looking only at the financial crisis, the fraction of EUREPO compared to the total KfW-BUND spread is even slightly smaller. As EUREPO is an offer rate, one fourth 
should therefore be an absolute upper bound of the non-liquidity related fraction of the illiquidity premium.

Finally, since BUNDs and KfW bonds are traded mainly over the counter and on electronic trading platforms like MTS, we test whether there are discrepancies between our exchange data and data from other platforms like MTS (for which we have one month of data) or Bloomberg Consensus quotes and do not find any fundamental difference.

\section{Term Structure Dynamics: A Conditional Approach}

We are now ready to study the term structure of illiquidity premiums in a regime-switching model and to analyze economic determinants of illiquidity premiums of different maturities conditional on the economic environment.

\subsection{MOTIVATION}

As can be seen in Figure 1, the behavior of illiquidity premiums seems to be heavily affected by the financial crisis. Illiquidity premiums of all maturities strongly increase in summer 2007 and reach all time highs after the collapse of Lehman Brothers. ${ }^{4}$ In the literature, we find both theoretical and empirical evidence for a regime-switching behavior of bond prices with respect to liquidity. So Acharya, Amihud, and Bharath (2010) analyze the influence of illiquidity on returns of corporate bonds of different rating classes with a Markov regime-switching model. They find that in the stress regime, prices of investment grade bonds rise and prices of speculative grade bonds fall with deteriorating liquidity

\footnotetext{
${ }^{4}$ The regime-switching behavior is supported by looking at Augmented Dickey Fuller (ADF) tests. They reject the non-stationary hypothesis for the time period before the beginning of the financial crisis in June 2007 for our three time series of illiquidity premiums, whereas if we include the whole time period, non-stationarity can only be rejected for two and five year illiquidity premiums. Additionally, Chow tests (see e.g., Candelon and Lütkepohl, 2001) reject the null hypothesis of parameter constancy in autoregressive models of different lag length for a wide range of possible break dates and all three series.
} 
(flight-to-liquidity). In contrast, there is no significant effect of illiquidity on bond returns in normal times. In a different empirical framework, Füss, Gehrig, and Rindler (2012) find that risk perception regarding liquidity risk significantly changed due to the financial crisis. Furthermore, Acharya and Pedersen (2005) find high innovations of illiquidity (with the Amihud, 2002, measure) for American stocks during periods anecdotally characterized as liquidity crises (e.g., the Russian default and LTCM crisis).

There is also a small but growing body of research predicting a regime-switching behavior of liquidity from a theoretical point of view. Brunnermeier and Pedersen (2009) propose a model where they relate an asset's liquidity to the margin requirements of market makers. If funding becomes scarce e.g., due to macroeconomic shocks, margin requirements are increasing which affects the market makers' ability to provide liquidity. The deteriorating liquidity in turn leads to higher asset volatility, which again leads to higher margin requirements. These liquidity spirals result in multiple fragile liquidity equilibria in crisis times. In a similar spirit, Gârleanu and Pedersen (2007) propose a model relating tighter risk-management and deteriorating liquidity. They predict a multiplier effect, which explains sudden dry ups of liquidity after initial losses. Another factor could be an increased risk aversion during crisis times, which would also lead to higher illiquidity premiums (see e.g., Acharya, Amihud, and Bharath, 2010). Increasing risk premiums in times of crisis when intermediaries are constrained in raising capital can be observed in the model of $\mathrm{He}$ and Krishnamurthy (2010). All of this would lead to a higher level and a higher volatility of illiquidity premiums during crisis times.

Based on these considerations there are good reasons to expect valuable insights from a regime-switching approach: a small number of separated regimes is reasonable and the system seems to alternate between them. Ignoring a possible different behavior of illiquidity premiums in different economic regimes can in the best case only lead to results describing 'average' characteristics. Our study is the first to allow explicitly for a regime dependent behavior of illiquidity premiums and their determinants. 


\subsection{CRISIS IDENTIFICATION}

We use a Markov regime-switching model for crisis identification which has been first proposed by Hamilton (1989). In contrast to our approach, most authors rely on exceptional events to identify crises (see e.g., Friewald, Jankowitsch, and Subrahmanyam, 2012; Chordia, Sarkar, and Subrahmanyam, 2005), but this procedure is somewhat arbitrary especially for the crisis end date (see Barrell et al., 2010 for a short discussion of this topic). The main advantage of the Markov approach is the endogenous crisis identification. So essentially the data tell us, when the system is likely to be in the stress regime. To validate the crisis identification, we relate our endogenously derived stress probabilities to macroeconomic and financial sector variables typically used to identify financial crises. Since crisis identification is a crucial step in our analysis, we also check the robustness of our results using exogenously specified crisis periods in Section 4 ..

To analyze the different behavior of illiquidity premiums conditional on crisis and noncrisis times, we estimate a two-regime AR model for two, five, and eight year illiquidity premiums. This model is then augmented with additional explanatory variables in Section 3.3.

$$
\begin{aligned}
& i l l i q_{t}(2)=a_{0, s}^{\text {Short }}+\sum_{i=1}^{p}\left(b_{i, s}^{\text {Short }} \text { illiq }_{t-i}(2)\right)+\epsilon_{s, t}^{\text {Short }}, \\
& i \operatorname{lliq}_{t}(5)=a_{0, s}^{\text {Medium }}+\sum_{i=1}^{p}\left(b_{i, s}^{\text {Medium }} i l l i q_{t-i}(5)\right)+\epsilon_{s, t}^{\text {Medium }}, \\
& i l l i q_{t}(8)=a_{0, s}^{\text {Long }}+\sum_{i=1}^{p}\left(b_{i, s}^{\text {Long }} \text { illiq }_{t-i}(8)\right)+\epsilon_{s, t}^{\text {Long }},
\end{aligned}
$$

where the state $s \in\{1,2\}$ follows a homogeneous Markov chain with constant transition probabilities

$$
\begin{aligned}
& P\left(s_{t}=1 \mid s_{t-1}=1\right)=p_{1,1}, \\
& P\left(s_{t}=2 \mid s_{t-1}=2\right)=p_{2,2} .
\end{aligned}
$$


The vector of error terms $\left(\epsilon_{s, t}^{\text {Short }}, \epsilon_{s, t}^{\text {Medium }}, \epsilon_{s, t}^{\text {Long }}\right)$ is multi-normally distributed with mean zero and variance-covariance matrix $\Omega_{s}$ where

$$
\Omega_{s}=\left(\begin{array}{ccc}
\left(\sigma_{s}^{\text {Short }}\right)^{2} & \rho_{s}^{\text {Short }, \text { Med. }} \cdot \sigma_{s}^{\text {Short }} \cdot \sigma_{s}^{\text {Med. }} & \rho_{s}^{\text {Short }, \text { Long }} \cdot \sigma_{s}^{\text {Short }} \cdot \sigma_{s}^{\text {Long }} \\
\rho_{s}^{\text {Short }, \text { Med. } .} \cdot \sigma_{s}^{\text {Short }} \cdot \sigma_{s}^{\text {Med. }} & \left(\sigma_{s}^{\text {Med. }}\right)^{2} & \rho_{s}^{\text {Med.,Long }} \cdot \sigma_{s}^{\text {Med. }} \cdot \sigma_{s}^{\text {Long }} \\
\rho_{s}^{\text {Short }, \text { Long }} \cdot \sigma_{s}^{\text {Short }} \cdot \sigma_{s}^{\text {Long }} & \rho_{s}^{\text {Med.,Long }} \cdot \sigma_{s}^{\text {Med. }} \cdot \sigma_{s}^{\text {Long }} & \left(\sigma_{s}^{\text {Long }}\right)^{2}
\end{array}\right) .
$$

We select this flexible variance-covariance matrix to allow for heteroskedasticity between the two regimes. Also, correlations of the error terms of different segments can be regimeswitching. The model is estimated along the lines described in Hamilton (1990) and Hamilton (1994) using the expectation-maximization (EM) algorithm to maximize the log-likelihood function.

Table III gives the estimation results of Model (4)-(8) with $p=3$ lags which is suggested by both Akaike's Information Criterion (AIC) and the Bayesian Information Criterion (BIC). The large and significant values of the lagged parameters for all maturities and both regimes show the high persistence of illiquidity premiums over time. Figure 3 shows the average term structure of illiquidity premiums in both regimes. A clear separation in the two regimes can be recognized. Whereas in the non-stress regime (regime 1), on average the extra yield to maturity of an illiquid KfW bond compared to the liquid BUND is around $15 \mathrm{bps}$, this illiquidity premium nearly doubles in the stress regime (regime 2). Additionally, the standard deviation of the innovations is about two to three times larger in the stress regime. The shape of the term structure is slightly U-shaped in both regimes, but the decreasing part is much more pronounced in the stress regime due to large shortterm illiquidity premiums. This result can be explained with flight-to-liquidity periods that coincide with financial crises. Within these periods, investors seek for short-term and extremely liquid bonds as a safe haven to temporarily store their funds. ${ }^{5}$

\footnotetext{
${ }^{5}$ We check the validity of these results by looking at the unbiasedness of our yield curve estimates for the bond with the shortest maturity: In the stress (normal times) regime, the yield of the shortest
} 
The estimation of the parameters delivers the probability of the system being in the stress regime for each date in the sample. This probability is plotted in Figure 4. The stress regime can be clearly associated with economic events that might be causal for poor liquidity. So the 1998 bailout of LTCM, the period after the burst of the dot-com bubble as well as the financial crisis starting in summer 2007 are all identified as stress periods.

\author{
[Insert Table III about here.] \\ [Insert Figure 3 about here.] \\ [Insert Figure 4 about here.]
}

To check the reliability of our crisis identification, we formally establish the connection between the liquidity stress regime and economic and financial sector variables typically associated with stress periods (see e.g., Acharya, Amihud, and Bharath, 2010). Accordingly, we regress the probability of being in the stress regime on the following variables: (i) Recession Dummy Germany: This dummy variable equals 1 if the observation date lies within at least two consecutive quarters of negative real GDP growth in Germany (seasonally and working-day adjusted data from Deutsche Bundesbank).

(ii) Negative Return DAX: Dummy variable that equals 1 if the three month return of the German stock market index DAX is below the one standard deviation bound calculated from realized five minute returns of the DAX from 1996 to September 2010 (data from Deutsche Börse).

(iii) VDAX New: Implied volatility of the DAX for the next 30 days calculated from options on futures on the stock market index (data from Deutsche Börse).

maturity BUND is on average 7.4 (3.2) bps below the estimated BUND yield curve, whereas the respective KfW bond lies 6.5 (2.2) bps above the KfW yield curve. This suggests an even stronger flight to the highly liquid BUND with the shortest time to maturity and means that we underestimate the illiquidity premium (and the increase of the illiquidity premium in the stress regime) at the very short end of the term structure. 
(iv) ZEW German Expectation: ZEW indicator of economic sentiment that measures the expectations of approximately 400 surveyed financial analysts regarding the future economic development (data from the Centre for European Economic Research (ZEW)).

(v) TED Spread: Spread between the unsecured three month USD Libor and the three month T-Bill rate. This spread measures the uncertainty in the banking system (see e.g., Brunnermeier, 2009) (data from Bloomberg).

(vi) Credit Spread: Spread between the yields of one year AA rated corporate bonds and $\mathrm{BBB}$ rated corporate bonds. It is assumed that credit spreads widen in times of economic stress (data from Bloomberg for the US bond market since European data only becomes available after 2001).

(vii) Capitalization of the Banking System: Yearly change in the total assets of the banking system (only commercial banks) divided by the total financial assets of households and non-financial corporations (data from Deutsche Bundesbank). This measure is motivated by the connection between the ability of banks to provide funding and market liquidity (see Brunnermeier and Pedersen, 2009).

(viii) Systemic Stress: Indicator of systemic stress in the financial system developed by Holló, Kremer, and Duca (2011) (data from the ECB).

The estimation results in Table IV show a clear connection between economic variables typically associated with economic stress and the probability of being in the stress regime. The OLS estimates are all significant in the expected direction. So a recession in Germany, the three month DAX return being below the one standard deviation bound, an increased implied volatility, large credit spreads and TED spreads as well as a high level of systemic stress all indicate a higher probability of being in the low liquidity stress regime. On the other hand, a more positive economic outlook and an increased capitalization of the banking system lead to lower stress probabilities. ${ }^{6}$ In the univariate regressions, the large

\footnotetext{
${ }^{6}$ However, the effect of the increased capitalization of the banking system only becomes significant if we control for implied volatility. A possible reason for this is that increased volatility might lead to higher capital requirements which in turn lead to an increased capitalization. So an increased capitalization is
} 
explanatory power of systemic stress for the probability to be in the stress regime could be expected since this indicator is specifically designed to identify financial crises. Together with the anecdotal evidence from Figure 4, this analysis confirms the capability of our approach to identify stress periods.

[Insert Table IV about here.]

\subsection{FACTORS INFLUENCING THE TERM STRUCTURE OF ILLIQUIDITY}

In this section, we analyze economic drivers of illiquidity premiums of different maturities conditional on crisis and non-crisis times. We select measures based on the theoretical and empirical literature regarding the determinants of illiquidity and illiquidity premiums. As illiquidity premiums are the extra yield investors receive for holding an illiquid bond, it is reasonable to hypothesize that they depend first on the degree of illiquidity of the respective bond and second on the preferences for liquidity of the marginal investor.

We account for the degree of illiquidity first with a measure of general market liquidity and second by directly looking at liquidity differences between KfW bonds and BUNDs. For the measure of general market liquidity, we follow the inventory holding cost paradigm dating back to Demsetz (1968), Stoll (1978), and Ho and Stoll (1981) and empirically validated e.g., by Benston and Hagerman (1974) and Bollen, Smith, and Whaley (2004) for the stock market and by Goyenko, Subrahmanyam, and Ukhov (2011) for the bond market. This paradigm states that increased asset volatility leads to larger bid-ask spreads to compensate the market makers for the incurred inventory risk and in turn should lead to increased illiquidity premiums (see e.g., Amihud and Mendelson, 1986). To proxy for the inventory risk of market makers, we use option implied interest rate volatility. Since coupon bonds are very similar to swaps in their cash flow structure, we use implied swaption volatilities from Bloomberg. They are derived according to Black's (1976) model also an indicator for increased volatility which would lead to contrary impacts on the stress probability if we do not control for volatility. 
from swaption prices with an option tenor of three months and a swap tenor of one, two, three, four, five, seven, and ten years. Since Black volatilities are heavily negatively correlated with the level of interest rates, but we do not want to incorporate interest rate effects, we orthogonalize the seven volatility series with the three-month Euribor. ${ }^{7}$ We use the first principal component of the seven orthogonalized series as our measure for inventory risk.

Liquidity differences between the two bond segments are proxied by differences in the outstanding volume that is freely available for trading. For this, we construct measures of the tradable volume of the representative two, five, and eight year KfW bond relative to the tradable volume of the corresponding German government bond. These measures are calculated in three steps. First, we adjust for the effect that the tradable volume and liquidity of a bond tends to decrease over its life due to the fact that the outstanding volume is absorbed by buy-and-hold investors (aging effect, see e.g., Warga, 1992). Ejsing and Sihvonen (2009) estimate for German government bonds that the trading volume of an issue declines by eight percent each year. Therefore, we multiply the outstanding volume of each bond with $e^{-0.08 \cdot \text { Age of the } \text { issue }_{t}}$. Second, we aggregate the tradable volume of all outstanding bonds from each segment into the tradable volume of three representative bonds (with two, five, and eight years time to maturity). ${ }^{8}$ Third, we divide the tradable volume of the representative KfW bond of each maturity by the tradable volume of the respective German government bond. As can be seen in Table V, the average

\footnotetext{
${ }^{7}$ The unconditional correlation between the seven implied volatility series and the three-month Euribor lies between -0.574 and -0.669 . For the time before the introduction of the Euro, we use Deutsche Mark swaption volatilities and orthogonalize them with the three-month Fibor (Frankfurt interbank offered rate).

${ }^{8}$ More precisely, we weight the volume of each bond with the influence it has on the zero coupon yield of the respective maturity. To measure this influence, we calculate the sensitivity of a small yield change of this bond on the zero coupon yield curve. The advantage of this weighting scheme is the independence from arbitrarily selected time to maturity bucket bounds. Additionally, it minimizes the time series variation resulting from bonds changing buckets.
} 
tradable volume of the representative KfW bond is about $20 \%$ of the volume of its BUND counterpart.

The selection of a measure for liquidity preferences is conceptually more difficult. On the one hand, it is obvious that future liquidation needs positively influence preferences for liquidity. On the other hand, it is likely that market wide risk premiums also impact the extra yield investors demand for holding an illiquid bond (see e.g., Gârleanu and Pedersen, 2011). As a proxy for future liquidation needs, we select the benchmark volatility index for the German stock market (VDAX New). As Kempf, Korn, and Uhrig-Homburg (2012) argue, implied volatility is a measure of the expected amount of information flowing into the market. It is likely that trading needs increase with a growing information flow. VDAX New is calculated by Deutsche Börse from options on futures on the DAX. As a further measure of financial uncertainty, which positively influences future liquidation needs, we use the TED spread. Brunnermeier (2009) points out, that in times of higher uncertainty in the banking system, the risk of unsecured loans rises which in turn leads to higher LIBOR rates. Additionally, in times of higher uncertainty the value of first rate collateral rises pushing down T-Bill rates and widening the TED spread further. ${ }^{9}$ As a proxy for market wide risk premiums or required returns, we select the dividend yield of the German stock market index DAX. In his 2011 Presidential Address to the American Finance Association, Cochrane (2011) points out that variations in the market wide dividend yield reflect changes in risk premiums rather than changes in future dividend growth. The dividend yield is calculated by Bloomberg under the assumption, that for all 30 constituents of the DAX, realized dividends in the year before the observation date are paid as an infinite annuity. It is available after May 7th, 1997. Both TED spread and VDAX New, besides being measures for uncertainty, are also expected to be sensitive to an increase in risk premiums. Additionally, the dividend yield is supposed to rise in uncertain times (with high future liquidation needs) due to declining stock prices. Thus,

\footnotetext{
${ }^{9}$ The TED spread as a measure of uncertainty, tightness, or fear in the banking system is also employed e.g., by Nyborg and Östberg (2010) and Kucuk (2009).
} 
a separation of liquidation needs and risk premiums is not possible and we therefore use the first principal component of the three series as our measure for liquidity preferences.

\section{[Insert Table V about here.]}

To analyze the impact of our economic factors on the term structure of illiquidity premiums conditional on the two regimes, we augment the AR Model (4)-(8) with exogenous variables. Sensitivities are allowed to be different in the two regimes:

$$
\begin{aligned}
\text { illiq }_{t}(2) & =a_{0, s}^{\text {Short }}+\sum_{i=1}^{p}\left(b_{i, s}^{\text {Short }} \text { illi }_{t-i}(2)\right)+a_{1, s}^{\text {Short }} \text { invRisk }_{t} \\
& +a_{2, s}^{\text {Short }} \operatorname{trblVol} l_{t}(2)+a_{3, s}^{\text {Short }} \text { liquPre }_{t}+\epsilon_{s, t}^{\text {Short }}, \\
\text { illiq }_{t}(5) & =a_{0, s}^{\text {Medium }}+\sum_{i=1}^{p}\left(b_{i, s}^{\text {Medium }} \text { illiq }_{t-i}(5)\right)+a_{1, s}^{\text {Medium }} \text { invRisk }_{t} \\
& +a_{2, s}^{\text {Medium }} \operatorname{trblVol}_{t}(5)+a_{3, s}^{\text {Medium }} \text { liquPref } f_{t}+\epsilon_{s, t}^{\text {Medium }}, \\
\text { illiq }_{t}(8) & =a_{0, s}^{\text {Long }}+\sum_{i=1}^{p}\left(b_{i, s}^{\text {Long }} \text { illiq }_{t-i}(8)\right)+a_{1, s}^{\text {Long }} \text { inv Risk }_{t} \\
& +a_{2, s}^{\text {Long }} \operatorname{trblVol}_{t}(8)+a_{3, s}^{\text {Long }} \text { liquPre }_{t}+\epsilon_{s, t}^{\text {Long }},
\end{aligned}
$$

where the state $s_{t} \in\{1,2\}$ follows a homogeneous Markov chain as specified in (7) and the vector of error terms $\left(\epsilon_{s, t}^{\text {Short }}, \epsilon_{s, t}^{\text {Medium }}, \epsilon_{s, t}^{\text {Long }}\right)$ is multi-normally distributed with mean zero and variance-covariance matrix as defined in (8). As in the Markov regime-switching AR model, we set $p=3$ and estimate the model with the EM algorithm to maximize the log-likelihood. Due to the availability of data for our exogenous variables, the observation period is now May 7th, 1997 to September 29th, 2010. ${ }^{10}$

Table VI presents our main results concerning the explanatory variables. First, inventory risk proxied by implied swaption volatilities heavily influences illiquidity premiums of all

\footnotetext{
${ }^{10}$ The derived stress probabilities are very similar to the ones calculated from the estimation of Model (4)-(8) (the average absolute difference between the two probability series is only $2.6 \%$ ) and they also expose the same crisis events (LTCM, burst of dot-com bubble, and financial crisis)
} 
maturities in the crisis regime, whereas in normal times, there is no significant influence. In Table VII, we analyze the regime-switching behavior of the sensitivities. The null hypotheses are that the influences of the economic factors on illiquidity premiums are identical in both regimes. For inventory risk, the null hypotheses (i.e., $H_{0}: a_{1, s=1}^{\text {Short }}=a_{1, s=2}^{\text {Short }}$, $a_{1, s=1}^{\text {Medium }}=a_{1, s=2}^{\text {Medium }}$, and $\left.a_{1, s=1}^{\text {Long }}=a_{1, s=2}^{\text {Long }}\right)$ can be clearly rejected for medium- and long-term premiums. The more important influence of inventory risk in crisis times is consistent with Brunnermeier and Pedersen's (2009) argument that it is much more costly for market makers to put aside the additional capital required to cover potential losses on their inventory positions when funding is scarce. Thus, they cut back liquidity provision more strongly during crisis times, when inventory risk increases. ${ }^{11}$ To illustrate the economic significance, we look at a one standard deviation shock on inventory risk. Such a shock leads to an increase e.g., of the medium-term premium of about $2.7 \mathrm{bps}$, which is more than one tenth of the average premium in the stress regime.

[Insert Table VI about here.]

[Insert Table VII about here.]

Second, liquidity differences, proxied by the fraction of tradable volume of the representative KfW bond compared to its BUND counterpart, only play a minor role. Although a large tradable volume of the KfW seems to significantly decrease the five year illiquidity premium, the economic significance is weak (a one standard deviation shock has only an impact of $0.7 \mathrm{bps})$. A similar result is also observed for the Pfandbrief market by Kempf, Korn, and Uhrig-Homburg (2012). A possible explanation the authors provide is that perceived liquidity differences do not change with each issued bond but are rather static.

\footnotetext{
${ }^{11}$ An alternative explanation is that the sensitivity of illiquidity premiums regarding a changing liquidity increases in crisis times. This is observed for the corporate bond market by Dick-Nielsen, Feldhütter, and Lando (2012) for the recent subprime crisis. Van Landschoot (2008) finds that the effect of changes to bid-ask spreads on corporate bond spreads is higher when liquidity is low.
} 
Another explanation could be that the value investors attribute to liquidity increases with less available liquid BUNDs due to the law of supply and demand (see Krishnamurthy and Vissing-Jorgensen, 2010). If this is the case, there are two opposite effects from an increase of the BUND volume. First, the relative liquidity of KfW bonds decreases leading to an increase in illiquidity premiums. Second, the value of liquidity decreases which should decrease illiquidity premiums.

Third, coefficients on preferences for liquidity clearly document that investors concentrate on short-term bonds when disengaging from illiquid securities in crisis times. The effect is both statistically and economically significant. A one standard deviation shock to the preference variable leads to an impact on the two year illiquidity premium of $3.1 \mathrm{bps}$ in the crisis regime. This is about $10 \%$ of the average premium in this regime. Moreover, the regime-switching impact of the preferences variable on the short end is confirmed by Table VII. In contrast, coefficients are insignificant both in normal times and for longer maturities. These results are particularly interesting as they constitute pronounced termstructure effects. The increased demand for short-term and highly liquid securities within stress periods leads first to a strongly increased level of especially short-term illiquidity premiums (see Figure 3). Second, amplified by the increased wariness to bear risks within stress periods, effects stemming from liquidity demand become more important.

Note that our analysis does not simply exclude credit risk effects, by definition. Instead, the close link between credit and liquidity risk (see e.g., Ericsson and Renault, 2006; He and Xiong, 2012) is well recognized in our approach as economy wide credit spreads have significant explanatory power for the probability to be in the liquidity stress regime (see Table IV). Despite this strong connection the specific nature of our data allows us to identify effects on illiquidity premiums. As a result, we can isolate flight-to-liquidity effects from the impacts of flight-to-quality and can conclude that they are especially pronounced at the short end. 
Overall, our results confirm the prediction of the theoretical literature (see e.g., Brunnermeier and Pedersen, 2009) that the impact of changes in fundamentals on illiquidity premiums is significantly stronger when funding is tight and the system is in stress. Moreover, flight- to-liquidity effects contribute to declining term structures of illiquidity premiums in crisis times. Thus, calibrating e.g., risk management models in normal times, when the influence of fundamentals on illiquidity premiums is weak, strongly underestimates the contribution of illiquidity to systematic risk and might systematically misjudge term structure effects.

\section{Robustness}

In this section, we perform several robustness checks, in which we control for perceived credit risk, selling and buying pressure from abroad, specialness of German government bonds, and the level of interest rates. Additionally we look at the influence of the principal component analysis on our results, incorporate possible spill-over effects between different segments of the term structure, and account for the degree of liquidity with quoted bid-ask spread differences allowing us to further check the separation between liquidity preferences and inventory risk. Finally, we use month-end data and exogenously specified crises dates to check the robustness against our regime identification methodology.

First, we include a measure for the market wide credit spread as an additional explanatory variable to control for perceived credit risk. We use the spread between the Bloomberg index for the yield of BBB rated industrial USD bonds and the corresponding AA index. Note that we cannot utilize credit spreads of EUR bonds since these are available only after August 2001. The credit spread indexes are available with different maturities, so we add the index with the corresponding time to maturity to the respective equation for the short-, medium-, and long-term illiquidity premium. Other than that, the model specification is identical to that in Table VI. 
The results are presented in Table VIII. The parameter estimates for our explanatory variables are qualitatively and quantitatively similar while all coefficients on credit spreads are insignificant. Importantly, this evidence suggests that our results are not driven by perceived credit risk. Together with the result, that the credit spread has significant explanatory power for the probability to be in the liquidity stress regime (see Table IV), this suggests that systematic credit and liquidity risk (even though heavily correlated) are only connected over the overall state of the economy.

\section{[Insert Table VIII about here.]}

Second, we control for selling and buying pressure from abroad. There are two channels through which effects might materialize. First, it is possible that foreign investors pull out of everything that is not as liquid as government bonds in times of stress. This would lead to a negative relation between foreign fund flows and the KfW-BUND spread. Second, it might be the case that foreign investments into the German bond market might be directed mainly into the government segment, resulting in a positive relation. To overcome the problem of these conflicting effects, we differentiate between foreign investments into bonds from public and non-public issuers, where Deutsche Bundesbank classifies the KfW as a non-public issuer. We use net fund flows published by Deutsche Bundesbank and deflate them with the consumer price index.

The results in Table IX reveal that foreign fund flows in (non-public) KfW bonds have indeed a significant negative effect on illiquidity premiums in the stress regime while flows in (public) government bonds are positively related to premiums. However, including these control variables does not change any of our previous findings.

\section{[Insert Table IX about here.]}

Third, we analyze a possible influence of specialness of BUNDs arising from their deliverability into the heavily traded interest rate future at Eurex. Although previous papers 
(see e.g., Ejsing and Sihvonen, 2009) conclude that these effects are close to an order of magnitude smaller than the observed illiquidity premiums, we want to exclude an influence on our results. For the robustness check, we focus on bonds with cheapest-to-deliver (CTD) status into the short- (BSA), medium- (Bobl), and long-term (Bund) futures. The value of specialness is calculated as the difference in the interpolated yield derived from the two BUNDs that enclose the CTD bond regarding its maturity minus the yield of the CTD bond (see Kempf, Korn, and Uhrig-Homburg, 2012).

According to Table $\mathrm{X}$ the value of specialness only significantly influences the yield spread between agency bonds and BUNDs for short- and medium-term maturities in normal times. Importantly, the similarity of the other results to our previous findings confirms that they are not an artifact of the specialness of BUNDs.

\section{[Insert Table X about here.]}

Fourth, we control for the influence of the level of interest rates on illiquidity premiums. If the marginal investor bases his investment decision on net present value, he discounts future illiquidity premiums and therefore, equilibrium premiums will be proportional to $\left(1+\right.$ risklessRate $\left._{t}\right)$ (see e.g., Yawitz, 1977). Additionally a lower interest rate today compared to higher interest rates in the past might increase the willingness of investors to take liquidity risk due to search for yield (see e.g., Rajan, 2006). We control for both effects by including the yield of all outstanding debt securities of German issuers. We look at the relative yield level compared to the average yield of the previous three years. The results in Table XI confirm our hypotheses regarding the average yield for mediumand long-term illiquidity premiums in the non-stress regime. Thus, in normal times investors seem to be more willing to take liquidity risks (and therefore drive illiquidity premiums down) when interest rates are low compared to the previous years. Controlling for the influence of interest rates, all significances for inventory risk, liquidity differences and liquidity preferences are unchanged compared to our main analysis. 
[Insert Table XI about here.]

Fifth, we check whether our results are governed by the use of first principal components as explanatory variables. Since we cannot observe inventory risk and liquidity preferences directly, the first principal component is used in our main analysis to reduce the noise in our proxies (see e.g., Ang and Piazzesi, 2003; Baker and Wurgler, 2006; Dick-Nielsen, Feldhütter, and Lando, 2012). To check whether this approach drives our findings, we use maturity dependent swaption volatilities for inventory risk ${ }^{12}$ and the dividend yield of the DAX as the measure for liquidity preferences.

Except for the fact that liquidity preferences are now even significant for medium-term maturities, Table XII confirms our main results. Hence, the choice of not directly observable principal components plays little role.

\section{[Insert Table XII about here.]}

Sixth, we control for dynamic linkages between illiquidity premiums of different maturities. Goyenko, Subrahmanyam, and Ukhov (2011) find for bid-ask spreads of US treasuries, that shocks on the liquidity of short-term bonds transmit to longer-term maturities, but they also observe transitions in the other direction. On the other hand, Kempf, Korn, and Uhrig-Homburg (2012) cannot detect any spill-over effects between different segments of the term structure for illiquidity premiums of German Pfandbriefe. We control for possible spill-over effects by including the lagged values of the other variables:

$$
\begin{aligned}
& i l l i q_{t}(2)=a_{0, s}^{\text {Short }}+\sum_{i=1}^{p}\left(b_{i, s}^{\text {Short }} i l l i q_{t-i}(2)\right) \\
& +\sum_{i=1}^{q}\left(c_{i, \text { Medium }, s}^{\text {Short }} i l l i q_{t-i}(5)+c_{i, \text { Long }, s}^{\text {Short }} i l l i q_{t-i}(8)\right) \\
& +a_{1, s}^{\text {Short }} \text { invRisk }_{t}+a_{2, s}^{\text {Short }} \operatorname{trblVol}_{t}(2)+a_{3, s}^{\text {Short }} \text { liquPref } f_{t}+\epsilon_{s, t}^{\text {Short }},
\end{aligned}
$$

\footnotetext{
${ }^{12}$ As a swaption with eight years swap tenor is not directly available, we linearly interpolate its implied volatility from the seven and ten year series.
} 


$$
\begin{aligned}
& i l l i q_{t}(5)=a_{0, s}^{\text {Medium }}+\sum_{i=1}^{p}\left(b_{i, s}^{\text {Medium }} i l l i q_{t-i}(5)\right) \\
& +\sum_{i=1}^{q}\left(c_{i, \text { Short }, s}^{\text {Medium }} i l l i q_{t-i}(2)+c_{i, \text { Long }, s}^{\text {Medium }} i l l i q_{t-i}(8)\right) \\
& +a_{1, s}^{\text {Medium }} \text { invRisk }_{t}+a_{2, s}^{\text {Medium }} \text { trblVol }_{t}(5)+a_{3, s}^{\text {Medium }} \text { liquPref } f_{t}+\epsilon_{s, t}^{\text {Medium }}, \\
& i l l i q_{t}(8)=a_{0, s}^{\text {Long }}+\sum_{i=1}^{p}\left(b_{i, s}^{\text {Long }} \text { illiq }_{t-i}(8)\right) \\
& +\sum_{i=1}^{q}\left(c_{i, \text { Short }, s}^{\text {Long }} i l l i q_{t-i}(2)+c_{i, \text { Medium }, s}^{\text {Long }} \text { illiq }_{t-i}(5)\right) \\
& +a_{1, s}^{\text {Long }} \text { invRisk }_{t}+a_{2, s}^{\text {Long }} \operatorname{trblVol}_{t}(8)+a_{3, s}^{\text {Long }} \text { liquPref } f_{t}+\epsilon_{s, t}^{\text {Long }},
\end{aligned}
$$

with the specifications for the transition matrix in Equation (7) and the variance-covariance matrix in (8) unchanged. We select $q=1$ lag as suggested by the Bayesian Information Criterion.

The results in Table XIII confirm our results for liquidity preferences and liquidity differences. Interestingly, the results for inventory risk are slightly weaker. Only mediumand long-term premiums are significantly influenced in the crisis regime. Since inventory risk drives all maturities in our main analysis, part of its impact seems to take effect over interdependencies between maturity segments.

\section{[Insert Table XIII about here.]}

Next, we use quoted bid-ask spread differences (see Figure 2) to account for the degree of liquidity. This allows us to further challenge our separation between liquidity preferences and inventory risk by including interest rate volatility into our proxy for liquidity preferences. ${ }^{13}$ In our main analysis, we employed inventory risk in the form of interest

\footnotetext{
${ }^{13}$ Interest rate volatilities, besides being measures for inventory risk that drive bid-ask spreads, are also a natural proxy for future trading needs. So e.g., Vayanos (2004) models liquidation needs of fund managers as the probability of the fund's performance falling below a threshold. This probability increases with volatility.
} 
rate volatility as a proxy for market liquidity and differences in the tradeable volume as the proxy for liquidity differences between KfWs and BUNDs. We did not use bid-ask spreads directly, since first, they are (like illiquidity premiums) measures for the price of liquidity and therefore possibly endogenous. Second, they are only available since August 22nd, 2001 on a continuous basis for all maturities.

Nevertheless, the results for the shortened observation period in Table XIV confirm our findings. Although the modified proxy for liquidity preferences is now statistically significant also for longer maturities and in the normal regime, its effect on short-term maturities in the stress regime is four times larger than in normal times and about twice as large compared to medium-term maturities. As inventory risk in our main analysis, bid-ask spread differences for all maturities are only significant in crises times.

\section{[Insert Table XIV about here.]}

Finally, we control for the crisis identification mechanism. As Boldin (1996) argues, the regime identification in Markov regime-switching models is sometimes vulnerable to relatively small changes in the data. To rule out such an effect in our study, we perform our analysis (a) with a new data set with month-end illiquidity premia and explanatory variables and (b) by exogenously specifying crisis and non-crisis periods.

The monthly analysis with the new data set in Table XV confirms all our main results. In the stress regime, the influence of inventory risk is significantly higher for mediumand long-term premiums. As before, liquidity preferences strongly influence short-term premiums. Although their influence now extends to medium-term premiums, the effect is more than twice as large for short-term maturities. As in the main analysis, tradeable volume is significant for medium-term premiums within the stress regime. Long-term maturities are now also affected.

[Insert Table XV about here.] 
For the exogenous crises specification, we define the LTCM crisis as the time between June and October 1998 (see Acharya and Pedersen, 2005). The beginning of the dot-com stress period is dated on May 10th, 2001, the day the ECB started cutting back interest rates. As the end of the crisis, we select the end of the 2002-03 recession in Germany in June 2003. The financial crisis starts in June 2007 when two of Bear Stearn's hedge funds ran into trouble and transforms into the European debt crisis which lasts up to the end of the observation period.

The results in Table XVI confirm our main findings. Inventory risk is significant for all maturities in crisis times, liquidity preferences are only significant in stress periods and for short-term maturities. Tradable volume is now significant for short-term premiums, but again, economic significances are below one basis point. Although conclusions do not change when using exogenously defined crisis dates, our approach to endogenously identify stress periods leads to a much cleaner separation of crisis- and non-crisis periods.

[Insert Table XVI about here.]

\section{Conclusion}

In this paper, we extract the term structure of illiquidity premiums from the spread between two bond classes differing only in their liquidity. The availability of a data set of homogeneous bonds spanning a large time to maturity segment over a long period of time allows us to quantify the term structure of illiquidity premiums without strong assumptions regarding the separation of credit and liquidity risk. We analyze this term structure in a setting allowing for a different behavior during crisis and non-crisis times. We find that the term structure of illiquidity premiums varies over time and is strongly dependent on the general financial and economic situation. Option implied interest rate volatilities as a measure for inventory risk influence all maturities, whereas our measure 
for liquidity preferences only impacts short-term maturities. The regression coefficients are regime-switching with a significant impact only in the stress regime.

Our findings imply that systematic liquidity risk is prone to be underestimated. Through its regime-switching behavior, the illiquidity discount increases sharply when the general state of the economy is bad. Additionally, the sensitivity of illiquidity premiums to fundamentals increases in crisis times. Ignoring one of these two channels systematically underestimates liquidity risk. From the issuer's perspective, our results show, that in times of crisis it is even more important to optimize the liquidity of an issue. ${ }^{14}$ This is particularly true in the light of systematically different term structure effects in crisis and non-crisis times.

\footnotetext{
${ }^{14}$ We have checked that issuing yields in the primary market for KfW bonds are relatively close to our yield curves estimated from secondary market prices.
} 


\section{References}

Acharya, V. V., Y. Amihud, and S. Bharath, 2010, Liquidity Risk of Corporate Bond Returns, Working Paper.

Acharya, V. V. and L. H. Pedersen, 2005, Asset Pricing with Liquidity Risk, Journal of Financial Economics 77 (2) pp. 375-410.

Amihud, Y., 2002, Illiquidity and Stock Returns: Cross-section and Time-Series Effects, Journal of Financial Markets 5 (1) pp. 31-56.

Amihud, Y. and H. Mendelson, 1986, Asset Pricing and the Bid-Ask Spread, Journal of Financial Economics 17 (2) pp. 223-249.

Amihud, Y. and H. Mendelson, 1991, Liquidity, Maturity, and the Yields on U.S. Treasury Securities, The Journal of Finance 46 (4) pp. 1411-1425.

Ang, A. and M. Piazzesi, 2003, A No-Arbitrage Vector Autoregression of Term Structure Dynamcis with Macroeconomic and Latent Variables, Journal of Monetary Economics 50 (4) pp. $745-787$.

Baker, M. and J. Wurgler, 2006, Investor Sentiment and the Cross-Section of Stock Returns, The Journal of Finance 61 (4) pp. 1645-1680.

Barrell, R., E. P. Davis, D. Karim, and I. Liadze, 2010, Bank Regulation, Property Prices and Early Warning Systems for Banking Crises in OECD Countries, Journal of Banking and Finance 34 (9) pp. 2255-2264.

Benston, G. J. and R. L. Hagerman, 1974, Determinants of Bid-Asked Spreads in the Over-The-Counter Market, Journal of Financial Economics 1 (4) pp. 353-364.

Black, F., 1976, The Pricing of Commodity Contracts, Journal of Financial Economics 3 (1-2) pp. 167-179.

Boldin, M. D., 1996, A Check on the Robustness of Hamilton's Markov Switching Model Approach to the Economic Analysis of the Business Cycle, Studies in Nonlinear Dynamcis 8 Econometrics 1 (1) pp. 35-46.

Bollen, N. P. B., T. Smith, and R. E. Whaley, 2004, Modeling the Bid/Ask Spread: Measuring the Inventory-Holding Premium, Journal of Financial Economics 72 (1) pp. $97-141$.

Brunnermeier, M. K., 2009, Deciphering the Liquidity and Credit Crunch 2007-2008, Journal of Economic Perspectives 23 (1) pp. 77-100. 
Brunnermeier, M. K. and L. H. Pedersen, 2009, Market Liquidity and Funding Liquidity, The Review of Financial Studies 22 (6) pp. 2201-2238.

Candelon, B. and H. Lütkepohl, 2001, On the Reliability of Chow-type Tests for Parameter Constancy in Multivariate Dynamic Models, Eocomics Letters 73 pp. 155-160.

Chordia, T., A. Sarkar, and A. Subrahmanyam, 2005, An Empirical Analysis of Stock and Bond Market Liquidity, The Review of Financial Studies 18 (1) pp. 85-129.

Cochrane, J. H, 2011, Presidential Address: Discount Rates, The Journal of Finance 66 (4) pp. 1047-1108.

Cox, D. R., 1970, The Analysis of Binary Data. (Methuen \& Co. Ltd., London).

de Jong, F. and J. Driessen, 2006, Liquidity Risk Premia in Corporate Bond Markets, Working Paper.

Demsetz, H., 1968, The Cost of Transacting, The Quarterly Journal of Economics 82 (1) pp. $33-53$.

Dick-Nielsen, J., P. Feldhütter, and D. Lando, 2012, Corporate Bond Liquidity Before and After the Onset of the Subprime Crisis, Journal of Financial Economics 103 (3) pp. 471-492.

Diebold, F. X. and C. Li, 2006, Forecasting the Term Structure of Government Bond Yields, Journal of Econometrics 130 (2) pp. 337-364.

Ejsing, J. W. and J. Sihvonen, 2009, Liquidity Premia in German Government Bonds, ECB Working Paper Series No. 1081.

Ericsson, J. and O. Renault, 2006, Liquidity and Credit Risk, The Journal of Finance 61 (5) pp. 2219-2250.

Feldhütter, P., 2012, The Same Bond at Different Prices: Identifying Search Frictions and Selling Pressure, The Review of Financial Studies 25 (4) pp. 1155-1206.

Friewald, N., R. Jankowitsch, and M. G. Subrahmanyam, 2012, Illiquidity or Credit Deterioration: A Study of Liquidity in the US Corporate Bond Market during Financial Crises, Journal of Financial Economics 105 (1) pp. 18-36.

Füss, R., H. Gehrig, and P. B. Rindler, 2012, Scattered Trust - Did the 2007-08 Financial Crisis Change Risk Perceptions?, Working Paper. 
Goyenko, R., A. Subrahmanyam, and A. Ukhov, 2011, The Term Structure of Bond Market Liquidity and Its Implications for Expected Bond Returns, Journal of Financial and Quantitative Analysis 46 (1) pp. 111-139.

Gârleanu, N. and L. H. Pedersen, 2007, Liquidity and Risk Management, American Economic Review 97 (2) pp. 193-197.

Gârleanu, N. and L. H. Pedersen, 2011, Margin-based Asset Pricing and Deviations from the Law of One Price, The Review of Financial Studies 24 (6) pp. 1980-2022.

Hamilton, J. D., 1989, A New Approach to the Economic Analysis of Nonstationary Time Series and the Business Cycle, Econometrica 57 (2) pp. 357-384.

Hamilton, J. D., 1990, Analysis of Time Series Subject to Changes in Regime, Journal of Econometrics 45 pp. 39-70.

Hamilton, J. D., 1994, Time Series Analysis. (Princeton University Press).

He, Z. and A. Krishnamurthy, 2010, Intermediary Asset Pricing, Working Paper.

He, Z. and W. Xiong, 2012, Rollover Risk and Credit Risk, The Journal of Finance 67 (2) pp. 391-429.

Ho, T and H. R. Stoll, 1981, Optimal Dealer Pricing Under Transactions and Return Uncertainty, Journal of Financial Economics 9 (1) pp. 47-73.

Holló, D., M. Kremer, and M. Lo Duca, 2011, CISS - A Composite Indicator of Systemic Stress in the Financial System, Working Paper.

Kempf, A., O. Korn, and M. Uhrig-Homburg, 2012, The Term Structure of Illiquidity Premia, Journal of Banking and Finance 36 (5) pp. 1381-1391.

Koziol, C. and P. Sauerbier, 2007, Valuation of Bond Illiquidity: An Option-Theoretical Approach, Journal of Fixed Income 16 (4) pp. 81-107.

Krishnamurthy, A. and A. Vissing-Jorgensen, 2010, The Aggregate Demand for Treasury Debt, Working Paper.

Kucuk, U. N., 2009, Dynamic Sources of Sovereign Bond Market Liquidity, Working Paper.

Liu, J., F. A. Longstaff, and R. E. Mandell, 2006, The Market Price of Risk in Interest Rate Swaps: The Roles of Default and Liquidity Risks, Journal of Business 79 (5) pp. 2337-2359. 
Longstaff, F. A., 2004, The Flight-to-Liquidity Premium in U.S. Treasury Bond Prices, Journal of Business 77 (3) pp. 511-526.

Longstaff, F. A., S. Mithal, and E. Neis, 2005, Corporate Yield Spreads: Default Risk or Liquidity? New Evidence from the Credit Default Swap Market, The Journal of Finance 60 (5) pp. 2213-2253.

Monfort, A. and J.-P. Renne, 2010, Default, Liquidity and Crises: an Econometric Framework, Working Paper.

Nelson, C. R. and A. F. Siegel, 1987, Parsimonious Modeling of Yield Curves, Journal of Business 60 (4) pp. 473-489.

Newey, W. K. and K. D. West, 1987, A Simple, Positive Semi-Definite, Heteroskedasticity and Autocorrelation Consistent Covariance Matrix, Econometrica 55 (3) pp. 703-708.

Nyborg, K. G. and P. Östberg, 2010, Money and Liquidity in Financial Markets, Swiss Finance Institute Research Paper Series No. 10 - 25.

Rajan, G. Raghuram, 2006, Has Finance Made the World Riskier?, European Financial Management 12 (4) pp. 499-533.

Schich, S. T., 1997, Estimating the German Term Structure, Discussion paper 4/97, Economic Research Group of the Deutsche Bundesbank.

Schwarz, K., 2010, Mind the Gap: Disentangling Credit and Liquidity in Risk Spreads, Working Paper.

Stoll, H. R., 1978, The Supply of Dealer Services in Securities Markets, The Journal of Finance 33 (4) pp. 1133-1151.

Van Landschoot, A., 2008, Determinants of Yield Spread Dynamics: Euro Versus US Dollar Corporate Bonds, Journal of Banking and Finance 34 (12) pp. 2597-2605.

Vayanos, D., 2004, Flight to Quality, Flight to Liquidity, and the Pricing of Risk, Working Paper.

Warga, A., 1992, Bond Returns, Liquidity, and Missing Data, Journal of Financial and Quantitative Analysis 27 (4) pp. 605-617.

White, H., 1982, Maximum Likelihood Estimation of Misspecified Models, Econometrica 50 (1) pp. 1-25.

Yawitz, Jess B., 1977, An Analytical Model of Interest Rate Differentials and Different Default Recoveries, Journal of Financial and Quantitative Analysis 12 (3) pp. 481-490. 


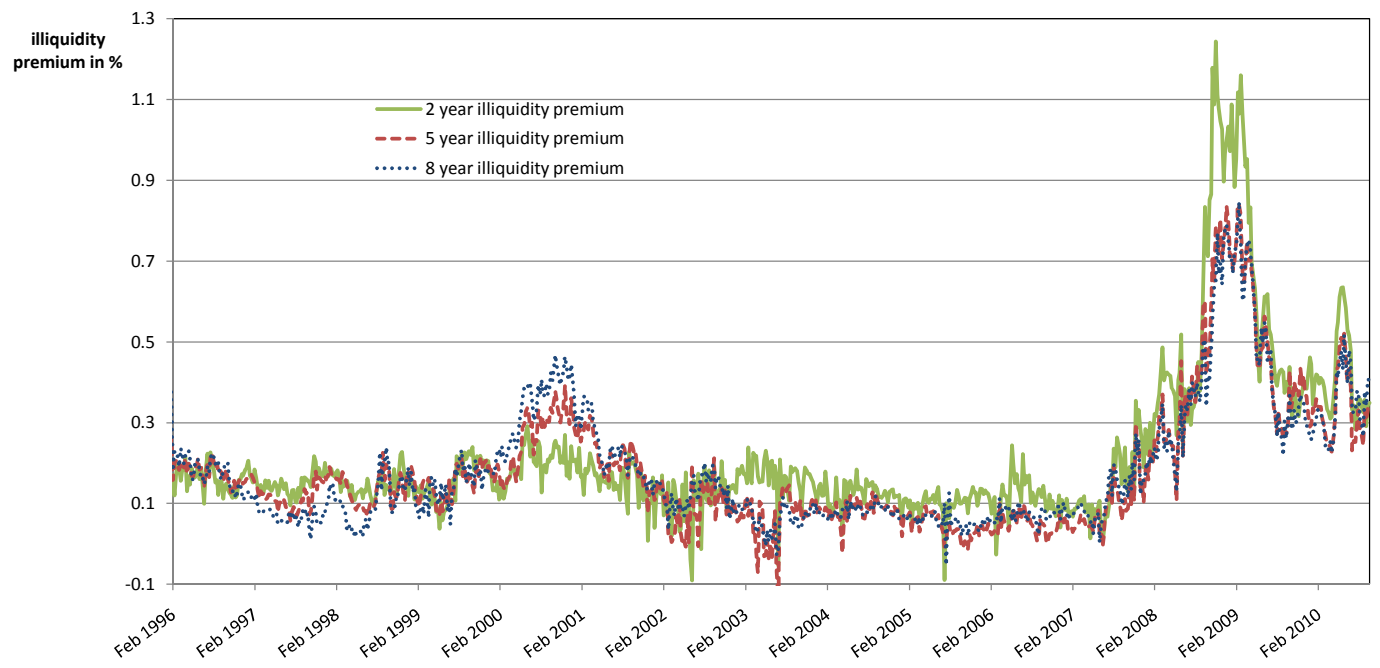

Figure 1: Illiquidity Premiums of Different Maturities

This figure shows the development of illiquidity premiums over time. The solid line depicts a time to maturity of two years, the dashed line provides five years, and the dotted line eight years time to maturity. The observation period is from February 14th, 1996 to September 29th, 2010 (764 weekly observations). 

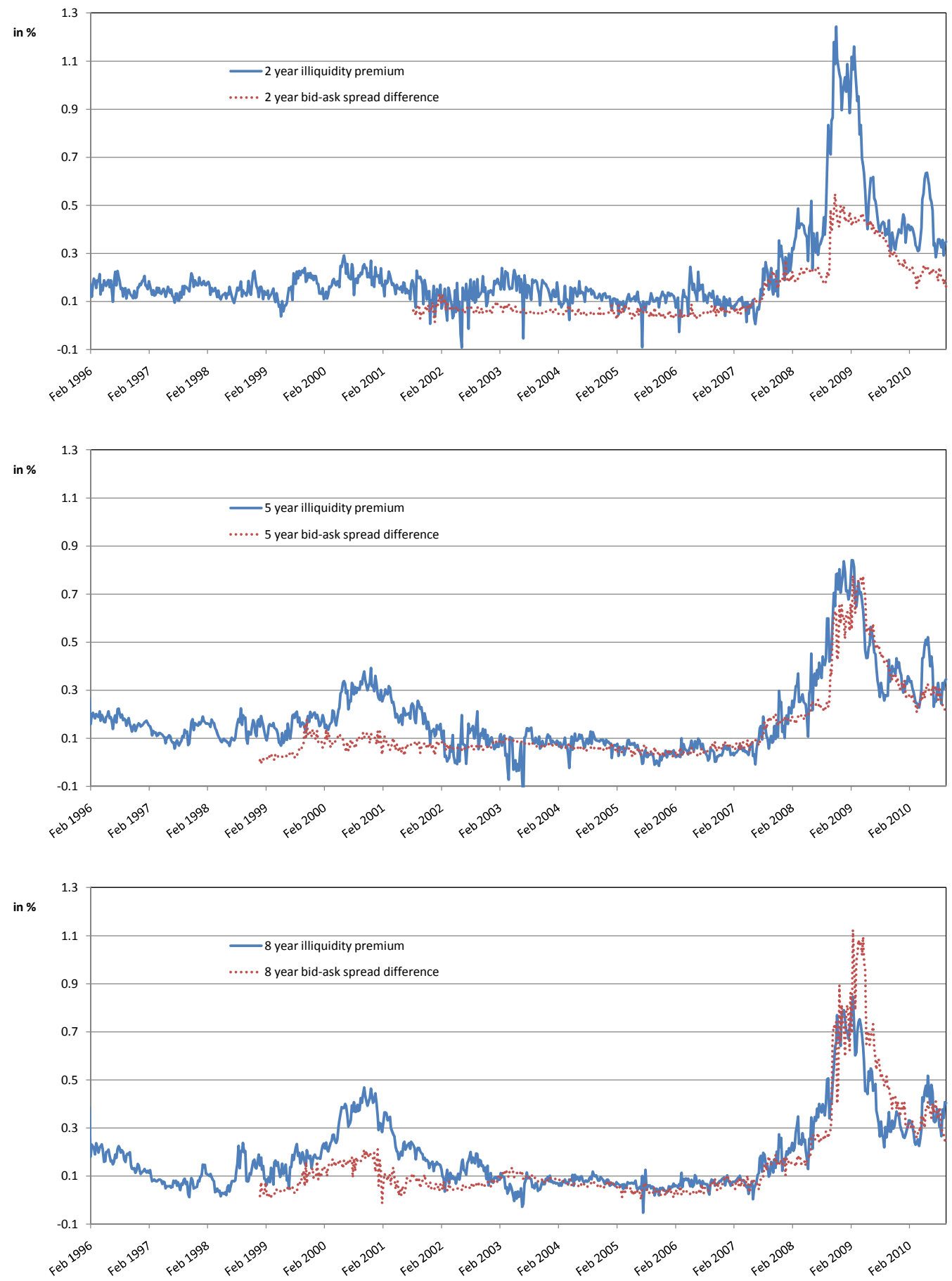

Figure 2: Illiquidity Premiums and Quoted Bid-Ask Spreads

This figure shows the development of illiquidity premiums (solid lines) and quoted relative bid-ask spread differences between KfW bonds and BUNDs (dotted lines) over time. The upper graph depicts a time to maturity of two years, the middle graph provides five years, and the lower graph eight years time to maturity. The observation period is from February 14th, 1996 to September 29th, 2010 (764 weekly observations). 


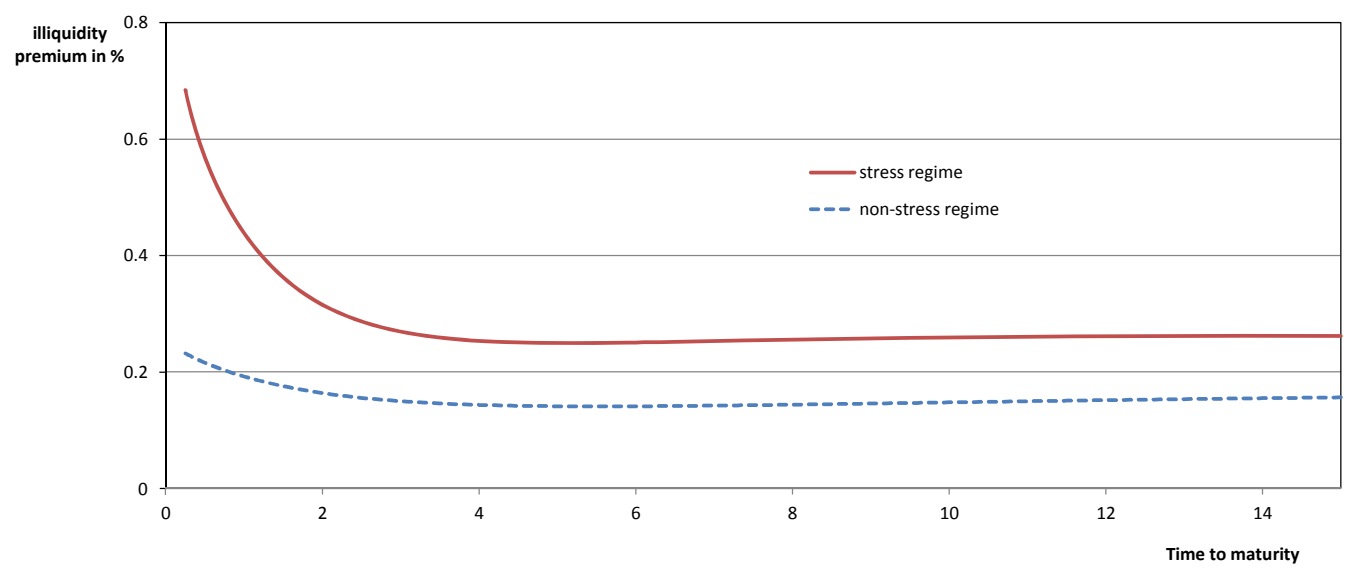

Figure 3: Shapes of Illiquidity Premiums in Different Regimes

This figure shows the shapes of the term structure of illiquidity premiums in the stress regime (solid line) and in the non-stress regime (dashed line). The average term structure of illiquidity premiums in one regime is calculated by weighting the term structure of each day with the probability to be in that regime on that date.

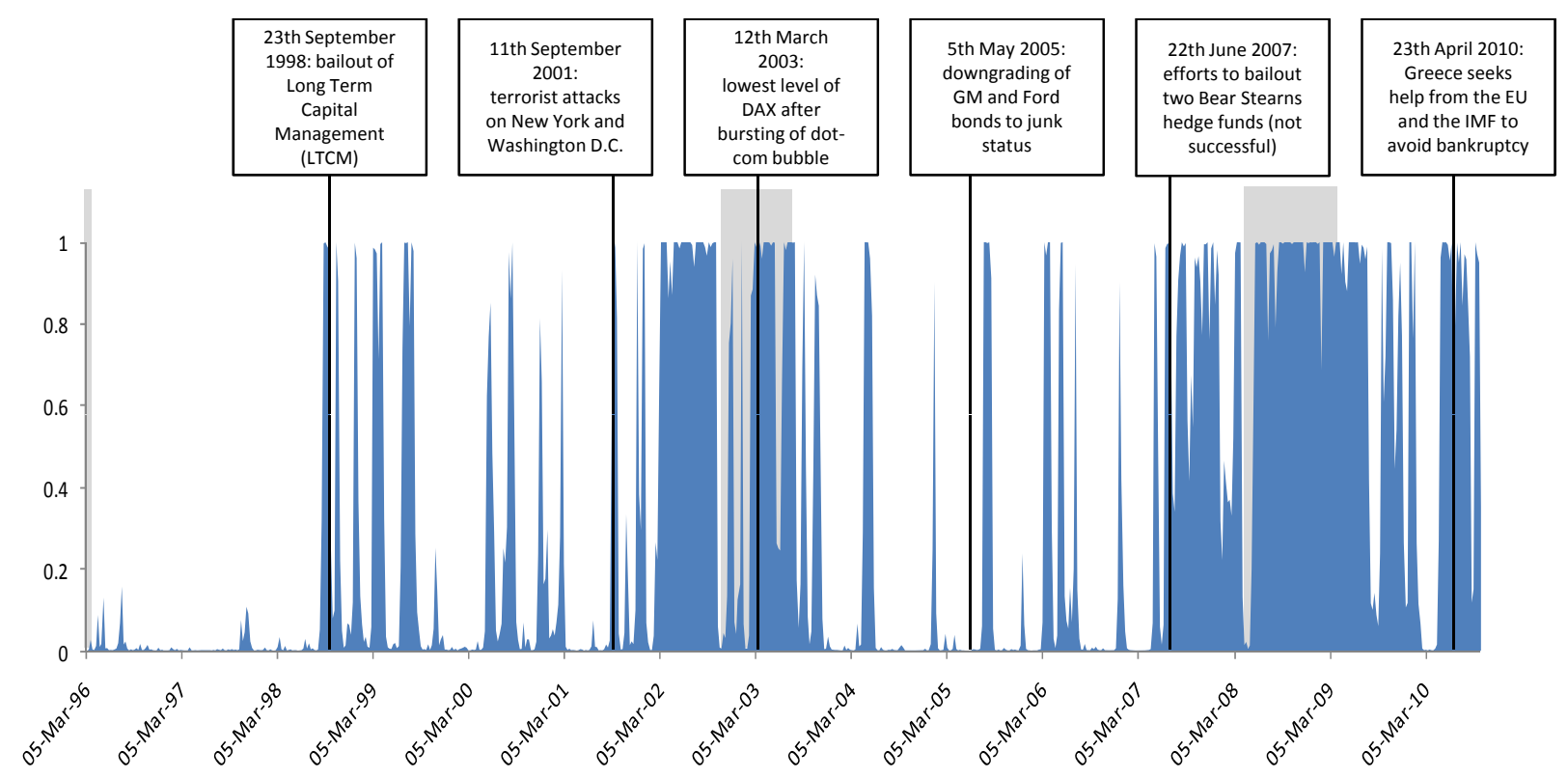

Figure 4: Endogenously Derived Probability to be in the Stress Regime

This figure shows the probability of being in the stress regime (regime 2) estimated from the Markov regime-switching Model (4)-(8) with three lags. Additionally, events anecdotally linked to financial stress or low liquidity are marked. Recessions, defined as at least two consecutive quarters of negative real GDP growth in Germany (Q1 1996, Q4 2002 Q2 2003, and Q2 2008 - Q1 2009) are shaded. 
Table I: Summary Statistics for KfW Bonds and BUNDs

This table shows summary statistics for the bonds included in the sample. The observation period is February 14th, 1996 to September 29th, 2010.

\begin{tabular}{lcc}
\hline & $\begin{array}{c}\text { Kreditanstalt für } \\
\text { Wiederaufbau (KfW) }\end{array}$ & $\begin{array}{c}\text { German government } \\
\text { bonds (BUND) }\end{array}$ \\
\hline Number of bonds & 68 & 227 \\
Average time to maturity & 6.09 & 7.52 \\
at issue date (in years) & & 4.90 \\
Average coupon (in \%) & 4.13 & 9.83 \\
Average issuing volume (incl. & 2.99 & 2231 \\
all reopenings) (in bn EUR) & & 203 \\
Total volume (in bn EUR) & 209 & \\
\hline
\end{tabular}

Table II: Fitting Errors

This table shows the distribution of observations over different maturity segments, average root mean square errors (RMSE), and mean estimation errors of the yield curve estimation in Equation (2). The observation period is February 14th, 1996 to September 29th, 2010.

\begin{tabular}{|c|c|c|c|c|c|c|}
\hline & \multicolumn{2}{|c|}{$\begin{array}{c}\text { Distribution of } \\
\text { observations }\end{array}$} & \multicolumn{2}{|c|}{ Average RMSE } & \multicolumn{2}{|c|}{$\begin{array}{c}\text { Mean estimation } \\
\text { error }\end{array}$} \\
\hline & KfW & BUND & KfW & BUND & KfW & BUND \\
\hline$T \leq 2$ years & $30.3 \%$ & $34.9 \%$ & $9.2 \mathrm{bps}$ & $5.0 \mathrm{bps}$ & $0.6 \mathrm{bps}$ & $-0.4 \mathrm{bps}$ \\
\hline 2 years $<T \leq 5$ years & $34.6 \%$ & $30.2 \%$ & $5.8 \mathrm{bps}$ & $4.3 \mathrm{bps}$ & $-1.1 \mathrm{bps}$ & $-0.2 \mathrm{bps}$ \\
\hline 5 years $<T \leq 8$ years & $17.2 \%$ & $13.0 \%$ & $4.0 \mathrm{bps}$ & $3.9 \mathrm{bps}$ & $0.2 \mathrm{bps}$ & $1.8 \mathrm{bps}$ \\
\hline 8 years $<T$ & $18.0 \%$ & $21.9 \%$ & $3.5 \mathrm{bps}$ & $6.9 \mathrm{bps}$ & $0.9 \mathrm{bps}$ & $-0.3 \mathrm{bps}$ \\
\hline All & $100.0 \%$ & $100.0 \%$ & $7.3 \mathrm{bps}$ & $5.5 \mathrm{bps}$ & $0.0 \mathrm{bps}$ & $0.0 \mathrm{bps}$ \\
\hline
\end{tabular}


Table III: Estimation Results for Markov Regime-Switching AR Model

This table shows the results of the maximum likelihood estimation of Model (4)-(8) with three lags. White's (1982) standard errors are given in parentheses. ${ }^{*},{ }^{*} *$ indicate significance at the $5 \%$ or 1\% level. The observation period is February 14th, 1996 to September 29 th, 2010.

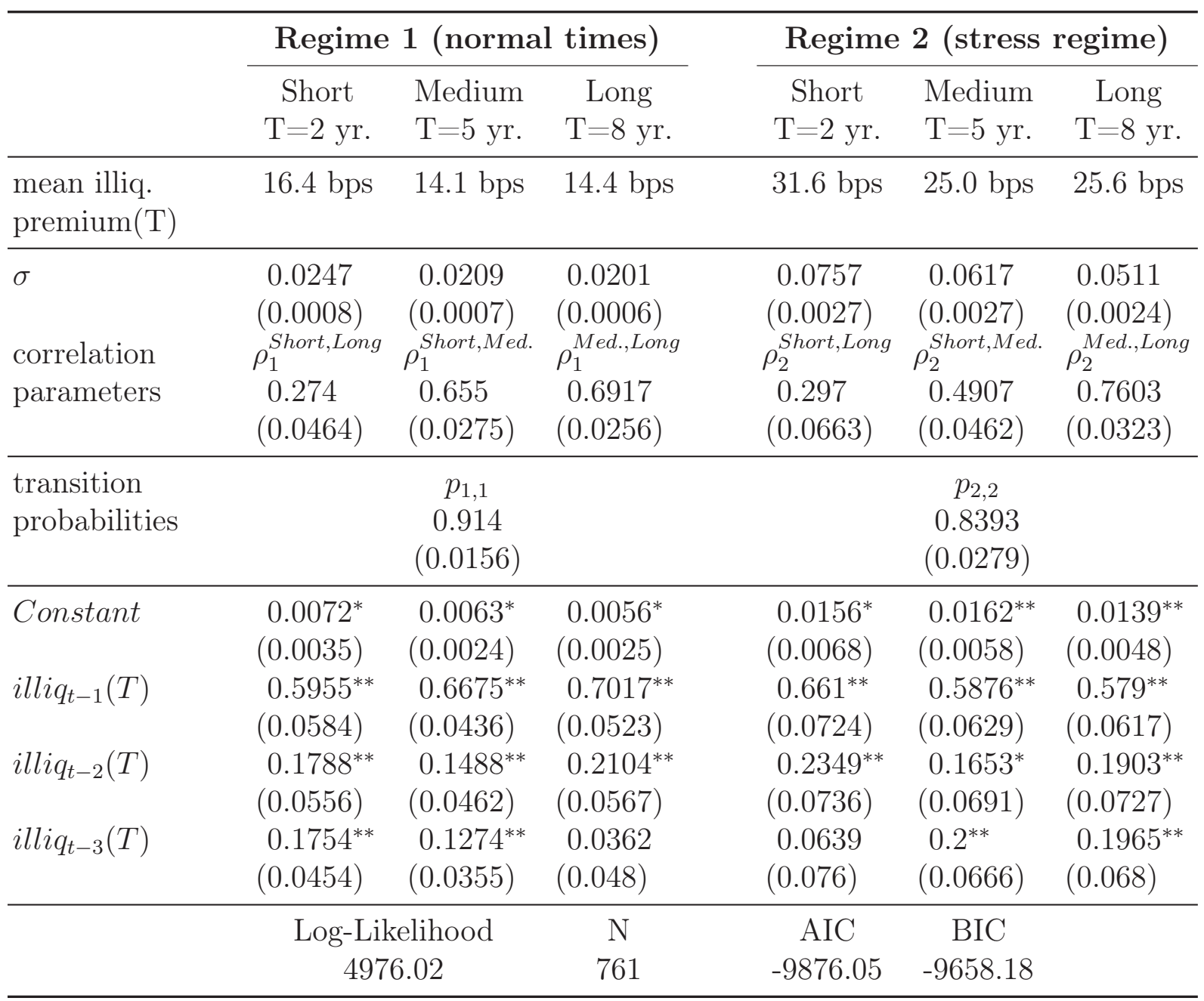




\section{Table IV: Model for the Probability of being in the Stress Regime}

This table shows OLS estimates for regressions where the dependent variable is a modified logit transformation $z_{t}=$ $\log \left(\frac{P_{t}^{\text {Stress }}+0.5 / N}{1-P_{t}^{\text {Stress }}+0.5 / N}\right)$ of the probability to be in the stress regime $P_{t}^{\text {Stress }}$. The modification term $\frac{0.5}{N}$ (with $N=761$ as the total number of observations) ensures that $z_{t}$ is defined for probabilities $P_{t}^{\text {Stress }}$ of 0 and 1 (see e.g., Cox, 1970; Acharya, Amihud, and Bharath, 2010). $P_{t}^{\text {Stress }}$ is estimated from the Markov regime-switching Model (4)-(8) with three lags. This variable is regressed on different economic and financial sector variables as described in the text. Standard errors are given in parentheses. $*$, ** indicate significance at the $5 \%$ or $1 \%$ level. The observation period is February 14th, 1996 to September 29 th, 2010 (761 weekly observations).

\begin{tabular}{|c|c|c|c|c|c|c|c|c|c|}
\hline & (1) & $(2)$ & $(3)$ & (4) & $(5)$ & $(6)$ & $(7)$ & (8) & (9) \\
\hline Constant & $\begin{array}{c}-2.0021^{* *} \\
(0.1767)\end{array}$ & $\begin{array}{c}-1.9169^{* *} \\
(0.1779)\end{array}$ & $\begin{array}{c}-6.5536^{* *} \\
(0.4212)\end{array}$ & $\begin{array}{c}-0.1791 \\
(0.2194)\end{array}$ & $\begin{array}{c}-2.8417^{* *} \\
(0.2545)\end{array}$ & $\begin{array}{c}-5.1469^{* *} \\
(0.2494)\end{array}$ & $\begin{array}{c}-6.8565^{* *} \\
(0.4262)\end{array}$ & $\begin{array}{r}-4.263^{* *} \\
(0.2104)\end{array}$ & $\begin{array}{c}-6.2873^{* *} \\
(0.5143)\end{array}$ \\
\hline Reces. Dummy Germ. & $\begin{array}{c}5.0563^{* *} \\
(0.5001)\end{array}$ & & & & & & & & $\begin{array}{c}0.6463 \\
(0.5958)\end{array}$ \\
\hline Negative Return DAX & & $\begin{array}{l}4.7216^{* *} \\
(0.5232)\end{array}$ & & & & & & & $\begin{array}{c}0.2118 \\
(0.5977)\end{array}$ \\
\hline VDAX New & & & $\begin{array}{c}20.2211^{* *} \\
(1.5225)\end{array}$ & & & & $\begin{array}{c}21.9046^{* *} \\
(1.5805)\end{array}$ & & $\begin{array}{l}8.7844^{* *} \\
(2.1382)\end{array}$ \\
\hline ZEW German Expec. & & & & $\begin{array}{r}-0.038^{* *} \\
(0.0045)\end{array}$ & & & & & $\begin{array}{c}-0.0069 \\
(0.0052)\end{array}$ \\
\hline TED Spread & & & & & $\begin{array}{c}2.837^{* *} \\
(0.3661)\end{array}$ & & & & $\begin{array}{c}0.6231 \\
(0.4345)\end{array}$ \\
\hline Credit Spread & & & & & & $\begin{array}{c}5.6568^{* *} \\
(0.3032)\end{array}$ & & & $\begin{array}{c}2.0641^{* *} \\
(0.6251)\end{array}$ \\
\hline Capitalization Bank. Syst. & & & & & & & $\begin{array}{c}-0.0833^{* *} \\
(0.023)\end{array}$ & & $\begin{array}{c}-0.0818^{* *} \\
(0.0271)\end{array}$ \\
\hline Systemic Stress & & & & & & & & $\begin{array}{c}16.1942^{* *} \\
(0.8539)\end{array}$ & $\begin{array}{c}6.7267^{* *} \\
(1.9347) \\
\end{array}$ \\
\hline Adjusted $R^{2}$ & 0.1176 & 0.0957 & 0.1875 & 0.085 & 0.0721 & 0.3135 & 0.2003 & 0.3206 & 0.373 \\
\hline
\end{tabular}


Table V: Summary Statistics of Explanatory Variables

This table shows summary statistics for the variables included in the analysis. invRisk refers to the first principal component of orthogonalized swaption volatilities of different maturities, $\operatorname{trblVol}(T)$ measures the tradable volume of the representative KfW bond compared to its BUND counterpart with $T$ years to maturity, and liquPref is the first principal component of the VDAX New, the TED spread, and the dividend yield of the DAX. The observation period is May 7th, 1997 to September 29th, 2010 (700 weekly observations).

\begin{tabular}{lccccc}
\hline & Mean & $\begin{array}{c}\text { Standard } \\
\text { Deviation }\end{array}$ & Minimum & Median & Maximum \\
\hline invRisk & 0 & 2.5519 & -3.9135 & -0.4477 & 14.9636 \\
$\operatorname{trblVol}(2)$ & 0.2117 & 0.0787 & 0.0838 & 0.2108 & 0.3782 \\
$\operatorname{trblVol}(5)$ & 0.2014 & 0.0544 & 0.0923 & 0.2051 & 0.3031 \\
$\operatorname{trblVol}(8)$ & 0.2321 & 0.0466 & 0.1336 & 0.2372 & 0.3328 \\
liquPref & 0 & 1.2989 & -1.6635 & -0.2836 & 7.8201 \\
\hline
\end{tabular}


Table VI: Estimation Results for Markov Regime-Switching AR with Exogenous Variables

This table shows the results of the maximum likelihood estimation of Model (9), (10), (11), (7), and (8) with $p=3$. White's (1982) standard errors are given in parentheses. *, ** indicate significance at the $5 \%$ or $1 \%$ level. The observation period is May 7 th, 1997 to September 29th, 2010.

\begin{tabular}{|c|c|c|c|c|c|c|}
\hline & \multicolumn{3}{|c|}{ Regime 1 (normal times) } & \multicolumn{3}{|c|}{ Regime 2 (stress regime) } \\
\hline & $\begin{array}{c}\text { Short } \\
\mathrm{T}=2 \mathrm{yr} .\end{array}$ & $\begin{array}{l}\text { Medium } \\
\mathrm{T}=5 \mathrm{yr} .\end{array}$ & $\begin{array}{c}\text { Long } \\
\mathrm{T}=8 \mathrm{yr} .\end{array}$ & $\begin{array}{c}\text { Short } \\
\mathrm{T}=2 \mathrm{yr} .\end{array}$ & $\begin{array}{l}\text { Medium } \\
\mathrm{T}=5 \mathrm{yr} .\end{array}$ & $\begin{array}{c}\text { Long } \\
\mathrm{T}=8 \mathrm{yr} .\end{array}$ \\
\hline $\begin{array}{l}\text { mean illiq. } \\
\text { premium }(\mathrm{T})\end{array}$ & $16.6 \mathrm{bps}$ & $14.0 \mathrm{bps}$ & $14.4 \mathrm{bps}$ & $31.5 \mathrm{bps}$ & $24.8 \mathrm{bps}$ & $25.4 \mathrm{bps}$ \\
\hline $\begin{array}{l}\text { correlation } \\
\text { parameters }\end{array}$ & $\begin{array}{c}0.0239 \\
(0.0019) \\
\rho_{1}^{\text {Short,Long }} \\
0.2892 \\
(0.0608)\end{array}$ & $\begin{array}{c}0.0216 \\
(0.0017) \\
\rho_{1}^{S h o r t, \text { Med. }} \\
0.6544 \\
(0.0429)\end{array}$ & $\begin{array}{c}0.0204 \\
(0.0015) \\
\rho_{1}^{M e d ., L o n g} \\
0.7052 \\
(0.0348)\end{array}$ & $\begin{array}{c}0.0709 \\
(0.0046) \\
\rho_{2}^{\text {Short }, \text { Long }} \\
0.3001 \\
(0.0707)\end{array}$ & $\begin{array}{c}0.0595 \\
(0.0037) \\
\rho_{2}^{\text {Short,Med. }} \\
0.4904 \\
(0.0647) \\
\end{array}$ & $\begin{array}{c}0.0501 \\
(0.0029) \\
\rho_{2}^{\text {Med..Long }} \\
0.7623 \\
(0.03)\end{array}$ \\
\hline $\begin{array}{l}\text { transition } \\
\text { probabilities }\end{array}$ & \multicolumn{3}{|c|}{$\begin{array}{c}p_{1,1} \\
0.9024 \\
(0.0229)\end{array}$} & \multicolumn{3}{|c|}{$\begin{array}{c}p_{2,2} \\
0.8384 \\
(0.0354)\end{array}$} \\
\hline Constant & $\begin{array}{l}0.0159^{* *} \\
(0.0053)\end{array}$ & $\begin{array}{c}0.0087 \\
(0.0056)\end{array}$ & $\begin{array}{c}0.0045 \\
(0.0066)\end{array}$ & $\begin{array}{c}0.0566^{* *} \\
(0.0143)\end{array}$ & $\begin{array}{c}0.0614^{* *} \\
(0.0141)\end{array}$ & $\begin{array}{c}0.0475^{*} \\
(0.0208)\end{array}$ \\
\hline$i l l i q_{t-1}(T)$ & $\begin{array}{c}0.5697^{* *} \\
(0.0558)\end{array}$ & $\begin{array}{c}0.6741^{* *} \\
(0.0482)\end{array}$ & $\begin{array}{c}0.7023^{* *} \\
(0.0537)\end{array}$ & $\begin{array}{c}0.539^{* *} \\
(0.0713)\end{array}$ & $\begin{array}{c}0.5136^{* *} \\
(0.0667)\end{array}$ & $\begin{array}{c}0.5248^{* *} \\
(0.0633)\end{array}$ \\
\hline$i l l i q_{t-2}(T)$ & $\begin{array}{l}0.1829^{* *} \\
(0.0522)\end{array}$ & $\begin{array}{c}0.152^{* *} \\
(0.0486)\end{array}$ & $\begin{array}{c}0.2349^{* *} \\
(0.0576)\end{array}$ & $\begin{array}{c}0.1834^{* *} \\
(0.0711)\end{array}$ & $\begin{array}{c}0.1213 \\
(0.0685)\end{array}$ & $\begin{array}{c}0.1477^{*} \\
(0.0715)\end{array}$ \\
\hline $\operatorname{illiq}_{t-3}(T)$ & $\begin{array}{l}0.1772^{* *} \\
(0.0409)\end{array}$ & $\begin{array}{r}0.116^{* *} \\
(0.0357)\end{array}$ & $\begin{array}{c}0.0158 \\
(0.0517)\end{array}$ & $\begin{array}{c}0.0499 \\
(0.067)\end{array}$ & $\begin{array}{c}0.1784^{* *} \\
(0.0641)\end{array}$ & $\begin{array}{c}0.1945^{* *} \\
(0.0695)\end{array}$ \\
\hline invRisk $_{t}$ & $\begin{array}{c}0.0027 \\
(0.0014)\end{array}$ & $\begin{array}{c}0.0004 \\
(0.0016)\end{array}$ & $\begin{array}{r}-0.0006 \\
(0.0015)\end{array}$ & $\begin{array}{c}0.0078^{*} \\
(0.0032)\end{array}$ & $\begin{array}{l}0.0105^{* *} \\
(0.0029)\end{array}$ & $\begin{array}{c}0.0094^{* *} \\
(0.0029)\end{array}$ \\
\hline $\operatorname{trblVol}_{t}(T)$ & $\begin{array}{c}-0.0035 \\
(0.0191)\end{array}$ & $\begin{array}{c}0.0042 \\
(0.0203)\end{array}$ & $\begin{array}{c}0.0095 \\
(0.0274)\end{array}$ & $\begin{array}{c}-0.0523 \\
(0.052)\end{array}$ & $\begin{array}{r}-0.1373^{*} \\
(0.0564)\end{array}$ & $\begin{array}{c}-0.0898 \\
(0.0823)\end{array}$ \\
\hline liquPref $f_{t}$ & $\begin{array}{c}0.003 \\
(0.0028) \\
\end{array}$ & $\begin{array}{c}0.0043 \\
(0.0026) \\
\end{array}$ & $\begin{array}{c}0.0031 \\
(0.0021) \\
\end{array}$ & $\begin{array}{c}0.0237^{* *} \\
(0.0072)\end{array}$ & $\begin{array}{c}0.003 \\
(0.0057) \\
\end{array}$ & $\begin{array}{c}-0.0015 \\
(0.0055)\end{array}$ \\
\hline & \multicolumn{2}{|c|}{$\begin{array}{c}\text { Log-Likelihood } \\
4539.48\end{array}$} & $\begin{array}{c}\mathrm{N} \\
700\end{array}$ & $\begin{array}{c}\text { AIC } \\
-8966.96\end{array}$ & $\begin{array}{c}\mathrm{BIC} \\
-8650.57\end{array}$ & \\
\hline
\end{tabular}


Table VII: Regime-Switching Behavior of Economic Determinants

This table shows the differences of the parameter estimates between the two regimes. The null hypothesis $H_{0}$ is, that parameter estimates are identical in both regimes, i.e., the difference is 0 . The Wald chi-squared statistics $W=(R \hat{\alpha}-r)^{\prime}\left(R \hat{V} R^{\prime}\right)^{-1}(R \hat{\alpha}-r)^{\prime}$ are given in square brackets, where $\mathrm{R}$ and $\mathrm{r}$ define the hypotheses for the parameter vector $\alpha . *, * *$ indicate rejection of $H_{0}$ at the $5 \%$ or $1 \%$ level. The observation period is May 7th, 1997 to September 29th, 2010.

\begin{tabular}{lccc}
\hline & \multicolumn{3}{c}{ Differences between regimes } \\
\cline { 2 - 4 } & Short & Medium & Long \\
& $\mathrm{T}=2 \mathrm{yr}$. & $\mathrm{T}=5 \mathrm{yr}$. & $\mathrm{T}=8 \mathrm{yr}$. \\
\hline Constant $: a_{0, s=1}-a_{0, s=2}$ & $0.0407^{* *}$ & $0.0527^{* *}$ & 0.043 \\
& {$[6.9765]$} & {$[10.9551]$} & {$[3.6066]$} \\
illiq $_{t-1}(T): b_{1, s=1}-b_{1, s=2}$ & -0.0307 & -0.1605 & -0.1775 \\
illiq $_{t-2}(T): b_{2, s=1}-b_{2, s=2}$ & {$[0.0983]$} & {$[3.305]$} & {$[3.7979]$} \\
illiq $_{t-3}(T): b_{3, s=1}-b_{3, s=2}$ & 0.0005 & -0.0307 & -0.0872 \\
invRisk $_{t}: a_{1, s=1}-a_{1, s=2}$ & {$[0.0000]$} & {$[0.1172]$} & {$[0.7633]$} \\
trblVol $_{t}(T): a_{2, s=1}-a_{2, s=2}$ & -0.1282 & 0.0624 & 0.1787 \\
liquPref $_{t}: a_{3, s=1}-a_{3, s=2}$ & {$[2.4831]$} & {$[0.6591]$} & {$[3.5548]$} \\
& 0.0051 & $0.0101^{* *}$ & $0.01^{* *}$ \\
& {$[1.9553]$} & {$[8.3308]$} & {$[8.4079]$} \\
& -0.0488 & $-0.1415^{*}$ & -0.0993 \\
& {$[0.7402]$} & {$[5.3063]$} & {$[1.1969]$} \\
& $0.0207^{* *}$ & -0.0013 & -0.0046 \\
& {$[6.9825]$} & {$[0.0395]$} & {$[0.5778]$} \\
\hline
\end{tabular}


Table VIII: Robustness Check: Credit Spread

This table shows the results of the maximum likelihood estimation of Model (9), (10), (11), (7), and (8) with $p=3$ including an additional variable controlling for perceived credit risk. Credit $(T)$ refers to the spread between the Bloomberg index for the yield of BBB rated industrial USD bonds and the corresponding AA index with $T$ years to maturity. White's (1982) standard errors are given in parentheses. ${ }^{*}, * *$ indicate significance at the $5 \%$ or 1\% level. The observation period is May 7th, 1997 to September 29th, 2010.

\begin{tabular}{|c|c|c|c|c|c|c|}
\hline & \multicolumn{3}{|c|}{ Regime 1 (normal times) } & \multicolumn{3}{|c|}{ Regime 2 (stress regime) } \\
\hline & $\begin{array}{c}\text { Short } \\
\mathrm{T}=2 \mathrm{yr} .\end{array}$ & $\begin{array}{l}\text { Medium } \\
\mathrm{T}=5 \mathrm{yr} .\end{array}$ & $\begin{array}{c}\text { Long } \\
\mathrm{T}=8 \mathrm{yr} .\end{array}$ & $\begin{array}{c}\text { Short } \\
\mathrm{T}=2 \mathrm{yr} .\end{array}$ & $\begin{array}{l}\text { Medium } \\
\mathrm{T}=5 \mathrm{yr} .\end{array}$ & $\begin{array}{c}\text { Long } \\
\mathrm{T}=8 \mathrm{yr} .\end{array}$ \\
\hline $\begin{array}{l}\text { mean illiq. } \\
\text { premium }(\mathrm{T})\end{array}$ & $16.6 \mathrm{bps}$ & $14.0 \mathrm{bps}$ & $14.4 \mathrm{bps}$ & $31.5 \mathrm{bps}$ & $24.8 \mathrm{bps}$ & $25.4 \mathrm{bps}$ \\
\hline $\begin{array}{l}\text { correlation } \\
\text { parameters }\end{array}$ & $\begin{array}{c}0.0241 \\
(0.0018) \\
\rho_{1}^{\text {Short }, \text { Long }} \\
0.2951 \\
(0.0591)\end{array}$ & $\begin{array}{c}0.0216 \\
(0.0017) \\
\rho_{1}^{\text {Short }, \text { Med. }} \\
0.6611 \\
(0.0409)\end{array}$ & $\begin{array}{c}0.0204 \\
(0.0015) \\
\rho_{1}^{\text {Med.,Long }} \\
0.7052 \\
(0.0335)\end{array}$ & $\begin{array}{c}0.0711 \\
(0.0045) \\
\rho_{2}^{\text {Short }, \text { Long }} \\
0.3086 \\
(0.0703)\end{array}$ & $\begin{array}{c}0.0596 \\
(0.0036) \\
\rho_{2}^{\text {Short }, \text { Med. }} \\
0.5027 \\
(0.0638)\end{array}$ & $\begin{array}{c}0.0503 \\
(0.0029) \\
\rho_{2}^{\text {Med.,Long }} \\
0.7636 \\
(0.0301)\end{array}$ \\
\hline $\begin{array}{l}\text { transition } \\
\text { probabilities }\end{array}$ & \multicolumn{3}{|c|}{$\begin{array}{c}p_{1,1} \\
0.9035 \\
(0.0215)\end{array}$} & \multicolumn{3}{|c|}{$\begin{array}{c}p_{2,2} \\
0.8386 \\
(0.0322)\end{array}$} \\
\hline Constant & $\begin{array}{r}0.0167^{*} \\
(0.0081)\end{array}$ & $\begin{array}{l}0.012 \\
(0.0079)\end{array}$ & $\begin{array}{c}0.0109 \\
(0.0094)\end{array}$ & $\begin{array}{c}0.0525^{* *} \\
(0.0143)\end{array}$ & $\begin{array}{c}0.0635^{* *} \\
(0.0157)\end{array}$ & $\begin{array}{c}0.0463 \\
(0.0249)\end{array}$ \\
\hline$i l l i q_{t-1}(T)$ & $\begin{array}{c}0.5664^{* *} \\
(0.0506)\end{array}$ & $\begin{array}{r}0.672^{* *} \\
(0.0483)\end{array}$ & $\begin{array}{c}0.7048^{* *} \\
(0.0542)\end{array}$ & $\begin{array}{l}0.5402^{* *} \\
(0.0711)\end{array}$ & $\begin{array}{c}0.5018^{* *} \\
(0.0672)\end{array}$ & $\begin{array}{l}0.5197^{* *} \\
(0.0641)\end{array}$ \\
\hline$i l l i q_{t-2}(T)$ & $\begin{array}{l}0.1847^{* *} \\
(0.049)\end{array}$ & $\begin{array}{l}0.1576^{* *} \\
(0.0492)\end{array}$ & $\begin{array}{l}0.2405^{* *} \\
(0.058)\end{array}$ & $\begin{array}{c}0.192^{* *} \\
(0.0716)\end{array}$ & $\begin{array}{c}0.1121 \\
(0.0689)\end{array}$ & $\begin{array}{c}0.1407 \\
(0.0726)\end{array}$ \\
\hline$i l l i q_{t-3}(T)$ & $\begin{array}{c}0.1744^{* *} \\
(0.0387)\end{array}$ & $\begin{array}{l}0.1227^{* *} \\
(0.0339)\end{array}$ & $\begin{array}{c}0.0126 \\
(0.0505)\end{array}$ & $\begin{array}{c}0.0717 \\
(0.0675)\end{array}$ & $\begin{array}{l}0.1676^{* *} \\
(0.0631)\end{array}$ & $\begin{array}{c}0.1963^{* *} \\
(0.0696)\end{array}$ \\
\hline invRisk $_{t}$ & $\begin{array}{c}0.0028 \\
(0.0018)\end{array}$ & $\begin{array}{c}0.0008 \\
(0.0019)\end{array}$ & $\begin{array}{c}0.0001 \\
(0.0019)\end{array}$ & $\begin{array}{r}0.0075^{*} \\
(0.0033)\end{array}$ & $\begin{array}{c}0.0108^{* *} \\
(0.0029)\end{array}$ & $\begin{array}{l}0.0095^{* *} \\
(0.0029)\end{array}$ \\
\hline $\operatorname{trblVol}_{t}(T)$ & $\begin{array}{r}-0.0086 \\
(0.0189)\end{array}$ & $\begin{array}{c}0.0214 \\
(0.0219)\end{array}$ & $\begin{array}{c}0.0123 \\
(0.0279)\end{array}$ & $\begin{array}{c}0.0058 \\
(0.0567)\end{array}$ & $\begin{array}{c}-0.1891^{* *} \\
(0.0638)\end{array}$ & $\begin{array}{c}-0.1021 \\
(0.0855)\end{array}$ \\
\hline liquPref $f_{t}$ & $\begin{array}{c}0.0025 \\
(0.0028)\end{array}$ & $\begin{array}{c}0.0057^{*} \\
(0.0027)\end{array}$ & $\begin{array}{c}0.0042 \\
(0.0023)\end{array}$ & $\begin{array}{l}0.0247^{* *} \\
(0.0073)\end{array}$ & $\begin{array}{c}0.0014 \\
(0.0059)\end{array}$ & $\begin{array}{c}-0.0022 \\
(0.0055)\end{array}$ \\
\hline Credit $_{t}(T)$ & $\begin{array}{c}0.0014 \\
(0.0098)\end{array}$ & $\begin{array}{c}-0.0111 \\
(0.0093)\end{array}$ & $\begin{array}{c}-0.0103 \\
(0.0095)\end{array}$ & $\begin{array}{c}-0.0195 \\
(0.0141)\end{array}$ & $\begin{array}{c}0.0177 \\
(0.0159)\end{array}$ & $\begin{array}{c}0.0077 \\
(0.0135)\end{array}$ \\
\hline & \multicolumn{2}{|c|}{$\begin{array}{c}\text { Log-Likelihood } \\
4543.63\end{array}$} & $\begin{array}{c}\mathrm{N} \\
700\end{array}$ & $\begin{array}{c}\text { AIC } \\
-8963.26\end{array}$ & $\begin{array}{c}\text { BIC } \\
-8612.97\end{array}$ & \\
\hline
\end{tabular}


Table IX: Robustness Check: Selling and Buying Pressure from Abroad

This table shows the results of the maximum likelihood estimation of Model (9), (10), (11), (7), and (8) with $p=3$ including two additional explanatory variables controlling for selling and buying pressure from abroad. ForeignPub (ForNonPub) is the deflated net investments of foreigners in bonds of public (non-public) issuers from Germany in trillions of Euros (in prices of 2005). Monthly values of this variable are from Deutsche Bundesbank and used for all weeks of the respective month. White's (1982) standard errors are given in parentheses. * ** indicate significance at the $5 \%$ or $1 \%$ level. The observation period is May 7th, 1997 to September 29th, 2010.

\begin{tabular}{|c|c|c|c|c|c|c|}
\hline & \multicolumn{3}{|c|}{ Regime 1 (normal times) } & \multicolumn{3}{|c|}{ Regime 2 (stress regime) } \\
\hline & $\begin{array}{c}\text { Short } \\
\mathrm{T}=2 \text { yr. }\end{array}$ & $\begin{array}{l}\text { Medium } \\
\mathrm{T}=5 \mathrm{yr} .\end{array}$ & $\begin{array}{c}\text { Long } \\
\mathrm{T}=8 \mathrm{yr} .\end{array}$ & $\begin{array}{c}\text { Short } \\
\mathrm{T}=2 \mathrm{yr} .\end{array}$ & $\begin{array}{l}\text { Medium } \\
\mathrm{T}=5 \mathrm{yr} .\end{array}$ & $\begin{array}{c}\text { Long } \\
\mathrm{T}=8 \mathrm{yr} .\end{array}$ \\
\hline $\begin{array}{l}\text { mean illiq. } \\
\text { premium(T) }\end{array}$ & $16.5 \mathrm{bps}$ & $14.0 \mathrm{bps}$ & $14.5 \mathrm{bps}$ & $31.7 \mathrm{bps}$ & $24.8 \mathrm{bps}$ & $25.3 \mathrm{bps}$ \\
\hline $\begin{array}{l}\text { correlation } \\
\text { parameters }\end{array}$ & $\begin{array}{c}0.0243 \\
(0.0018) \\
\rho_{1}^{\text {Short }, \text { Long }} \\
0.2958 \\
(0.063)\end{array}$ & $\begin{array}{c}0.0218 \\
(0.0016) \\
\rho_{1}^{\text {Short }, \text { Med }} \text {. } \\
0.6619 \\
(0.0403)\end{array}$ & $\begin{array}{c}0.0204 \\
(0.0015) \\
\rho_{1}^{\text {Med.,Long }} \\
0.7045 \\
(0.037)\end{array}$ & $\begin{array}{c}0.0702 \\
(0.0046) \\
\rho_{2}^{\text {Short }, \text { Long }} \\
0.2924 \\
(0.0722)\end{array}$ & $\begin{array}{c}0.0586 \\
(0.0035) \\
\rho_{2}^{\text {Short }, \text { Med. }} \\
0.483 \\
(0.0655)\end{array}$ & $\begin{array}{c}0.0496 \\
(0.0028) \\
\text { Med.,Long } \\
\rho_{2} \\
0.7605 \\
(0.0302)\end{array}$ \\
\hline $\begin{array}{l}\text { transition } \\
\text { probabilities }\end{array}$ & \multicolumn{3}{|c|}{$\begin{array}{c}p_{1,1} \\
0.9074 \\
(0.0204)\end{array}$} & \multicolumn{3}{|c|}{$\begin{array}{c}p_{2,2} \\
0.8442 \\
(0.0376)\end{array}$} \\
\hline Constant & $\begin{array}{c}0.0149^{*} \\
(0.0059)\end{array}$ & $\begin{array}{c}0.0079 \\
(0.0058)\end{array}$ & $\begin{array}{c}0.0035 \\
(0.0064)\end{array}$ & $\begin{array}{c}0.0746^{* *} \\
(0.0169)\end{array}$ & $\begin{array}{l}0.0802^{* *} \\
(0.017)\end{array}$ & $\begin{array}{c}0.0595^{* *} \\
(0.0224)\end{array}$ \\
\hline$i l l i q_{t-1}(T)$ & $\begin{array}{l}0.5584^{* *} \\
(0.0624)\end{array}$ & $\begin{array}{l}0.6659^{* *} \\
(0.0531)\end{array}$ & $\begin{array}{l}0.6986^{* *} \\
(0.0527)\end{array}$ & $\begin{array}{l}0.5206^{* *} \\
(0.0715)\end{array}$ & $\begin{array}{l}0.4897^{* *} \\
(0.0673)\end{array}$ & $\begin{array}{c}0.5035^{* *} \\
(0.0654)\end{array}$ \\
\hline$i l l i q_{t-2}(T)$ & $\begin{array}{l}0.1918^{* *} \\
(0.0506)\end{array}$ & $\begin{array}{l}0.1582^{* *} \\
(0.0486)\end{array}$ & $\begin{array}{c}0.2356^{* *} \\
(0.0657)\end{array}$ & $\begin{array}{r}0.1653^{*} \\
(0.0709)\end{array}$ & $\begin{array}{c}0.1044 \\
(0.0685)\end{array}$ & $\begin{array}{c}0.1365 \\
(0.0758)\end{array}$ \\
\hline$i l l i q_{t-3}(T)$ & $\begin{array}{l}0.1849^{* *} \\
(0.0416)\end{array}$ & $\begin{array}{l}0.1242^{* *} \\
(0.038)\end{array}$ & $\begin{array}{c}0.0257 \\
(0.0587)\end{array}$ & $\begin{array}{c}0.0315 \\
(0.0651)\end{array}$ & $\begin{array}{r}0.1506^{*} \\
(0.0629)\end{array}$ & $\begin{array}{r}0.1728^{*} \\
(0.0696)\end{array}$ \\
\hline${i n v R i s k_{t}}$ & $\begin{array}{c}0.0029 \\
(0.0017)\end{array}$ & $\begin{array}{c}0.0008 \\
(0.0025)\end{array}$ & $\begin{array}{c}-0.0002 \\
(0.0024)\end{array}$ & $\begin{array}{c}0.0071^{*} \\
(0.0033)\end{array}$ & $\begin{array}{c}0.0093^{* *} \\
(0.0031)\end{array}$ & $\begin{array}{c}0.0084^{* *} \\
(0.0032)\end{array}$ \\
\hline $\operatorname{trblVol} t(T)$ & $\begin{array}{c}-0.0032 \\
(0.0191)\end{array}$ & $\begin{array}{c}0.0057 \\
(0.0203)\end{array}$ & $\begin{array}{c}0.0102 \\
(0.0281)\end{array}$ & $\begin{array}{c}-0.0522 \\
(0.0536)\end{array}$ & $\begin{array}{c}-0.1589^{* *} \\
(0.0578)\end{array}$ & $\begin{array}{r}-0.0974 \\
(0.0837)\end{array}$ \\
\hline liquPref $f_{t}$ & $\begin{array}{c}0.0032 \\
(0.0028)\end{array}$ & $\begin{array}{c}0.0043 \\
(0.0026)\end{array}$ & $\begin{array}{c}0.003 \\
(0.0022)\end{array}$ & $\begin{array}{c}0.0273^{* *} \\
(0.0076)\end{array}$ & $\begin{array}{c}0.0068 \\
(0.0064)\end{array}$ & $\begin{array}{c}0.0014 \\
(0.0065)\end{array}$ \\
\hline ForeignPub & $\begin{array}{c}0.169 \\
(0.1931)\end{array}$ & $\begin{array}{c}0.3006 \\
(0.1829)\end{array}$ & $\begin{array}{c}0.3196 \\
(0.1886)\end{array}$ & $\begin{array}{c}0.5184 \\
(0.6899)\end{array}$ & $\begin{array}{c}1.1894^{*} \\
(0.5688)\end{array}$ & $\begin{array}{c}1.1294^{*} \\
(0.4949)\end{array}$ \\
\hline ForNonPub & $\begin{array}{c}0.0108 \\
(0.2382)\end{array}$ & $\begin{array}{c}-0.0613 \\
(0.2307)\end{array}$ & $\begin{array}{c}-0.0323 \\
(0.229)\end{array}$ & $\begin{array}{c}-1.8322^{* *} \\
(0.6782)\end{array}$ & $\begin{array}{c}-1.8724^{* *} \\
(0.6697)\end{array}$ & $\begin{array}{r}-1.4013^{*} \\
(0.6434)\end{array}$ \\
\hline & \multicolumn{2}{|c|}{$\begin{array}{c}\text { Log-Likelihood } \\
4550.2\end{array}$} & $\begin{array}{c}\mathrm{N} \\
700\end{array}$ & $\begin{array}{c}\text { AIC } \\
-8964.39\end{array}$ & $\begin{array}{c}\mathrm{BIC} \\
-8580.22\end{array}$ & \\
\hline
\end{tabular}


Table X: Robustness Check: Specialness

This table shows the results of the maximum likelihood estimation of Model (9), (10), (11), (7), and (8) with $p=3$ including an additional variable controlling for specialness of BUNDs. Special $t_{t}(T)$ refers to the cheapest-to-deliver (CTD) premium for the bond which is CTD into the BSA, Bobl, and Bund futures for $T=2, T=5$, and $T=8$ respectively. It is calculated as the yield spread between the interpolated yield derived from the two BUNDs that enclose the CTD bond regarding its maturity minus the yield of the CTD bond. White's (1982) standard errors are given in parentheses. * ** indicate significance at the $5 \%$ or $1 \%$ level. The observation period is May 7th, 1997 to September 29th, 2010.

\begin{tabular}{|c|c|c|c|c|c|c|}
\hline & \multicolumn{3}{|c|}{ Regime 1 (normal times) } & \multicolumn{3}{|c|}{ Regime 2 (stress regime) } \\
\hline & $\begin{array}{l}\text { Short } \\
\mathrm{T}=2 \mathrm{yr} .\end{array}$ & $\begin{array}{l}\text { Medium } \\
\mathrm{T}=5 \mathrm{yr} .\end{array}$ & $\begin{array}{l}\text { Long } \\
\mathrm{T}=8 \mathrm{yr} .\end{array}$ & $\begin{array}{l}\text { Short } \\
\mathrm{T}=2 \mathrm{yr} .\end{array}$ & $\begin{array}{l}\text { Medium } \\
\mathrm{T}=5 \mathrm{yr} .\end{array}$ & $\begin{array}{l}\text { Long } \\
\mathrm{T}=8 \mathrm{yr} .\end{array}$ \\
\hline $\begin{array}{l}\text { mean illiq. } \\
\text { premium(T) }\end{array}$ & $16.6 \mathrm{bps}$ & $14.0 \mathrm{bps}$ & $14.5 \mathrm{bps}$ & $31.6 \mathrm{bps}$ & $24.8 \mathrm{bps}$ & $25.3 \mathrm{bps}$ \\
\hline $\begin{array}{l}\text { correlation } \\
\text { parameters }\end{array}$ & $\begin{array}{c}0.0241 \\
(0.0018) \\
\rho_{1}^{\text {Short }, \text { Long }} \\
0.2969 \\
(0.0578)\end{array}$ & $\begin{array}{c}0.0219 \\
(0.0017) \\
\rho_{1}^{S h o r t, M e d .} \\
0.6635 \\
(0.0366) \\
\end{array}$ & $\begin{array}{c}0.0205 \\
(0.0015) \\
\rho_{1}^{\text {Med.,Long }} \\
0.7129 \\
(0.034)\end{array}$ & $\begin{array}{c}0.071 \\
(0.0047) \\
\rho_{2}^{\text {Short }, \text { Long }} \\
0.2994 \\
(0.071)\end{array}$ & $\begin{array}{c}0.0593 \\
(0.0037) \\
\rho_{2}^{\text {Short }, \text { Med }} . \\
0.4898 \\
(0.0646) \\
\end{array}$ & $\begin{array}{c}0.0502 \\
(0.003) \\
\rho_{2}^{\text {Med.,Long }} \\
0.7625 \\
(0.0306)\end{array}$ \\
\hline $\begin{array}{l}\text { transition } \\
\text { probabilities }\end{array}$ & \multicolumn{3}{|c|}{$\begin{array}{c}p_{1,1} \\
0.9045 \\
(0.0227)\end{array}$} & \multicolumn{3}{|c|}{$\begin{array}{c}p_{2,2} \\
0.8402 \\
(0.0338)\end{array}$} \\
\hline Constant & $\begin{array}{c}0.0159^{* *} \\
(0.0055)\end{array}$ & $\begin{array}{c}0.0095 \\
(0.0056)\end{array}$ & $\begin{array}{c}0.0048 \\
(0.0066)\end{array}$ & $\begin{array}{c}0.0563^{* *} \\
(0.0146)\end{array}$ & $\begin{array}{l}0.0638^{* *} \\
(0.0145)\end{array}$ & $\begin{array}{r}0.0462^{*} \\
(0.0226)\end{array}$ \\
\hline$i l l i q_{t-1}(T)$ & $\begin{array}{l}0.5691^{* *} \\
(0.0526)\end{array}$ & $\begin{array}{l}0.6698^{* *} \\
(0.0451)\end{array}$ & $\begin{array}{l}0.698^{* *} \\
(0.0551)\end{array}$ & $\begin{array}{l}0.5393^{* *} \\
(0.071)\end{array}$ & $\begin{array}{l}0.5081^{* *} \\
(0.0678)\end{array}$ & $\begin{array}{l}0.5198^{* *} \\
(0.065)\end{array}$ \\
\hline$i l l i q_{t-2}(T)$ & $\begin{array}{c}0.1849^{* *} \\
(0.0471)\end{array}$ & $\begin{array}{c}0.1555^{* *} \\
(0.0454)\end{array}$ & $\begin{array}{c}0.2387^{* *} \\
(0.0576)\end{array}$ & $\begin{array}{c}0.1856^{* *} \\
(0.0707)\end{array}$ & $\begin{array}{c}0.1167 \\
(0.0687)\end{array}$ & $\begin{array}{c}0.1464^{*} \\
(0.0711)\end{array}$ \\
\hline$i l l i q_{t-3}(T)$ & $\begin{array}{l}0.1737^{* *} \\
(0.0413)\end{array}$ & $\begin{array}{r}0.118^{* *} \\
(0.0346)\end{array}$ & $\begin{array}{c}0.0149 \\
(0.0503)\end{array}$ & $\begin{array}{c}0.0484 \\
(0.0669)\end{array}$ & $\begin{array}{l}0.1769^{* *} \\
(0.0641)\end{array}$ & $\begin{array}{l}0.1976^{* *} \\
(0.0701)\end{array}$ \\
\hline invRisk $_{t}$ & $\begin{array}{c}0.0026 \\
(0.0015)\end{array}$ & $\begin{array}{c}0.0005 \\
(0.0017)\end{array}$ & $\begin{array}{r}-0.0007 \\
(0.0015)\end{array}$ & $\begin{array}{r}0.0078^{*} \\
(0.0032)\end{array}$ & $\begin{array}{c}0.0107^{* *} \\
(0.0029)\end{array}$ & $\begin{array}{c}0.0095^{* *} \\
(0.0029)\end{array}$ \\
\hline $\operatorname{trblVol} l_{t}(T)$ & $\begin{array}{c}-0.0027 \\
(0.0204)\end{array}$ & $\begin{array}{c}-0.0003 \\
(0.0202)\end{array}$ & $\begin{array}{c}0.009 \\
(0.0266)\end{array}$ & $\begin{array}{c}-0.0522 \\
(0.0526)\end{array}$ & $\begin{array}{r}-0.1417^{*} \\
(0.0576)\end{array}$ & $\begin{array}{r}-0.0823 \\
(0.0916)\end{array}$ \\
\hline liquPref $f_{t}$ & $\begin{array}{c}0.0027 \\
(0.0029)\end{array}$ & $\begin{array}{c}0.0039 \\
(0.0028)\end{array}$ & $\begin{array}{c}0.0031 \\
(0.0022)\end{array}$ & $\begin{array}{c}0.0236^{* *} \\
(0.0072)\end{array}$ & $\begin{array}{c}0.0043 \\
(0.0058)\end{array}$ & $\begin{array}{c}-0.0013 \\
(0.0055)\end{array}$ \\
\hline $\operatorname{Special}_{t}(T)$ & $\begin{array}{c}0.05^{* *} \\
(0.0178)\end{array}$ & $\begin{array}{r}0.0535^{*} \\
(0.0227)\end{array}$ & $\begin{array}{c}0.0389 \\
(0.0419)\end{array}$ & $\begin{array}{c}0.0132 \\
(0.0678)\end{array}$ & $\begin{array}{r}-0.1235 \\
(0.0649)\end{array}$ & $\begin{array}{c}0.0201 \\
(0.1156)\end{array}$ \\
\hline & \multicolumn{2}{|c|}{$\begin{array}{l}\text { Log-Likelihood } \\
4546.65\end{array}$} & $\begin{array}{c}\mathrm{N} \\
700\end{array}$ & $\begin{array}{c}\text { AIC } \\
-8969.30\end{array}$ & $\begin{array}{c}\mathrm{BIC} \\
-8619.02\end{array}$ & \\
\hline
\end{tabular}


Table XI: Robustness Check: Level of Interest Rates

This table shows the results of the maximum likelihood estimation of Model (9), (10), (11), (7), and (8) with $p=3$ including an additional explanatory variable controlling for interest rate effects. AverYld is the yield of all outstanding bonds divided by the average yield of the previous three years (data from Deutsche Bundesbank). White's (1982) standard errors are given in parentheses. * ** indicate significance at the $5 \%$ or 1\% level. The observation period is May 7th, 1997 to September 29th, 2010.

\begin{tabular}{|c|c|c|c|c|c|c|}
\hline & \multicolumn{3}{|c|}{ Regime 1 (normal times) } & \multicolumn{3}{|c|}{ Regime 2 (stress regime) } \\
\hline & $\begin{array}{c}\text { Short } \\
\mathrm{T}=2 \mathrm{yr} .\end{array}$ & $\begin{array}{l}\text { Medium } \\
\mathrm{T}=5 \mathrm{yr} .\end{array}$ & $\begin{array}{l}\text { Long } \\
\mathrm{T}=8 \mathrm{yr} .\end{array}$ & $\begin{array}{l}\text { Short } \\
\mathrm{T}=2 \mathrm{yr} .\end{array}$ & $\begin{array}{l}\text { Medium } \\
\mathrm{T}=5 \mathrm{yr} .\end{array}$ & $\begin{array}{c}\text { Long } \\
\mathrm{T}=8 \mathrm{yr} .\end{array}$ \\
\hline $\begin{array}{l}\text { mean illiq. } \\
\text { premium(T) }\end{array}$ & $16.7 \mathrm{bps}$ & $14.1 \mathrm{bps}$ & $14.6 \mathrm{bps}$ & $31.7 \mathrm{bps}$ & $24.9 \mathrm{bps}$ & $25.3 \mathrm{bps}$ \\
\hline $\begin{array}{l}\text { correlation } \\
\text { parameters }\end{array}$ & $\begin{array}{c}0.0242 \\
(0.0015) \\
\rho_{1}^{\text {Short }, \text { Long }} \\
0.3089 \\
(0.0565)\end{array}$ & $\begin{array}{c}0.0218 \\
(0.0013) \\
\rho_{1}^{\text {Short }, \text { Med. }} \\
0.6677 \\
(0.0385)\end{array}$ & $\begin{array}{c}0.0203 \\
(0.0011) \\
\rho_{1}^{\text {Med.,Long }} \\
0.7103 \\
(0.0304)\end{array}$ & $\begin{array}{c}0.0713 \\
(0.0042) \\
\rho_{2}^{\text {Short }, \text { Long }} \\
0.2996 \\
(0.0707)\end{array}$ & $\begin{array}{c}0.0598 \\
(0.0035) \\
\rho_{2}^{\text {Short }, \text { Med }} . \\
0.4888 \\
(0.0645)\end{array}$ & $\begin{array}{c}0.0502 \\
(0.0029) \\
\rho_{2}^{\text {Med.,Long }} \\
0.7599 \\
(0.0305)\end{array}$ \\
\hline $\begin{array}{l}\text { transition } \\
\text { probabilities }\end{array}$ & \multicolumn{3}{|c|}{$\begin{array}{c}p_{1,1} \\
0.9054 \\
(0.0183)\end{array}$} & \multicolumn{3}{|c|}{$\begin{array}{c}p_{2,2} \\
0.8392 \\
(0.0322)\end{array}$} \\
\hline Constant & $\begin{array}{r}0.0255^{*} \\
(0.0119)\end{array}$ & $\begin{array}{l}-0.01 \\
(0.0095)\end{array}$ & $\begin{array}{r}-0.0244^{*} \\
(0.0096)\end{array}$ & $\begin{array}{r}0.0821^{*} \\
(0.0338)\end{array}$ & $\begin{array}{l}0.0804^{* *} \\
(0.0311)\end{array}$ & $\begin{array}{c}0.0544 \\
(0.0294)\end{array}$ \\
\hline$i_{l l i q_{t-1}}(T)$ & $\begin{array}{c}0.562^{* *} \\
(0.0504)\end{array}$ & $\begin{array}{c}0.6594^{* *} \\
(0.0475)\end{array}$ & $\begin{array}{c}0.6801^{* *} \\
(0.0525)\end{array}$ & $\begin{array}{c}0.5362^{* *} \\
(0.0715)\end{array}$ & $\begin{array}{c}0.5134^{* *} \\
(0.0671)\end{array}$ & $\begin{array}{c}0.5235^{* *} \\
(0.0622)\end{array}$ \\
\hline$i l l i q_{t-2}(T)$ & $\begin{array}{c}0.1811^{* *} \\
(0.0503)\end{array}$ & $\begin{array}{c}0.1491^{* *} \\
(0.0469)\end{array}$ & $\begin{array}{c}0.2294^{* *} \\
(0.0505)\end{array}$ & $\begin{array}{c}0.1807^{*} \\
(0.0704)\end{array}$ & $\begin{array}{c}0.1205 \\
(0.0686)\end{array}$ & $\begin{array}{c}0.1488^{*} \\
(0.0717)\end{array}$ \\
\hline$i l l i q_{t-3}(T)$ & $\begin{array}{l}0.1697^{* *} \\
(0.038)\end{array}$ & $\begin{array}{c}0.1182^{* *} \\
(0.0321)\end{array}$ & $\begin{array}{c}0.0266 \\
(0.0457)\end{array}$ & $\begin{array}{c}0.0476 \\
(0.0672)\end{array}$ & $\begin{array}{c}0.1771^{* *} \\
(0.0637)\end{array}$ & $\begin{array}{c}0.1938^{* *} \\
(0.0701)\end{array}$ \\
\hline$i_{n v R i s k_{t}}$ & $\begin{array}{r}0.0036^{*} \\
(0.0015)\end{array}$ & $\begin{array}{c}0.0007 \\
(0.0015)\end{array}$ & $\begin{array}{c}-0.0007 \\
(0.0014)\end{array}$ & $\begin{array}{r}0.0078^{*} \\
(0.0033)\end{array}$ & $\begin{array}{c}0.0103^{* *} \\
(0.0028)\end{array}$ & $\begin{array}{c}0.0093^{* *} \\
(0.0028)\end{array}$ \\
\hline $\operatorname{trblVol}_{t}(T)$ & $\begin{array}{c}-0.0184 \\
(0.0206)\end{array}$ & $\begin{array}{c}-0.0109 \\
(0.0212)\end{array}$ & $\begin{array}{c}0.0016 \\
(0.029)\end{array}$ & $\begin{array}{c}-0.0622 \\
(0.0553)\end{array}$ & $\begin{array}{r}-0.1359^{*} \\
(0.0577)\end{array}$ & $\begin{array}{c}-0.073 \\
(0.0804)\end{array}$ \\
\hline liquPref $f_{t}$ & $\begin{array}{c}0.0024 \\
(0.003)\end{array}$ & $\begin{array}{c}0.0049 \\
(0.0028)\end{array}$ & $\begin{array}{c}0.0043 \\
(0.0023)\end{array}$ & $\begin{array}{c}0.0247^{* *} \\
(0.0073)\end{array}$ & $\begin{array}{c}0.0035 \\
(0.0059)\end{array}$ & $\begin{array}{c}-0.0013 \\
(0.0056)\end{array}$ \\
\hline AverYld & $\begin{array}{l}-0.035 \\
(0.0101)\end{array}$ & $\begin{array}{c}0.0257^{*} \\
(0.0102)\end{array}$ & $\begin{array}{c}0.0354^{* *} \\
(0.0104)\end{array}$ & $\begin{array}{c}-0.0231 \\
(0.0279)\end{array}$ & $\begin{array}{c}-0.0204 \\
(0.028)\end{array}$ & $\begin{array}{c}-0.0119 \\
(0.0227)\end{array}$ \\
\hline & \multicolumn{2}{|c|}{$\begin{array}{c}\text { Log-Likelihood } \\
4551.81\end{array}$} & $\begin{array}{c}\mathrm{N} \\
700\end{array}$ & $\begin{array}{c}\mathrm{AIC} \\
-8979.63\end{array}$ & $\begin{array}{c}\mathrm{BIC} \\
-8629.35\end{array}$ & \\
\hline
\end{tabular}


Table XII: Robustness Check: Influence of Principal Component Analysis

This table shows the results of the maximum likelihood estimation of Model (9), (10), (11), (7), and (8) with $p=3$ with invRisk $k_{t}(T)$ instead of the first principal component inv Risk $k_{t}$ and DivYieldDax instead of liquPref. $i n v R i s k_{t}(T)$ is the implied volatility of swaptions with an option tenor of three months and a swap tenor of $T$ years orthogonalized with the three months Euribor (data from Bloomberg). DivYldDax is the value weighted dividend yield of the members of the German stock market index DAX (data from Bloomberg). White's (1982) standard errors are given in parentheses. ${ }^{*}, * *$ indicate significance at the $5 \%$ or 1\% level. The observation period is May 7th, 1997 to September 29th, 2010.

\begin{tabular}{|c|c|c|c|c|c|c|}
\hline & \multicolumn{3}{|c|}{ Regime 1 (normal times) } & \multicolumn{3}{|c|}{ Regime 2 (stress regime) } \\
\hline & $\begin{array}{l}\text { Short } \\
\mathrm{T}=2 \mathrm{yr} .\end{array}$ & $\begin{array}{l}\text { Medium } \\
\mathrm{T}=5 \mathrm{yr} .\end{array}$ & $\begin{array}{l}\text { Long } \\
\mathrm{T}=8 \mathrm{yr} \text {. }\end{array}$ & $\begin{array}{c}\text { Short } \\
\mathrm{T}=2 \mathrm{yr} .\end{array}$ & $\begin{array}{l}\text { Medium } \\
\mathrm{T}=5 \mathrm{yr} .\end{array}$ & $\begin{array}{l}\text { Long } \\
\mathrm{T}=8 \mathrm{yr} .\end{array}$ \\
\hline $\begin{array}{l}\text { mean illiq. } \\
\text { premium }(\mathrm{T})\end{array}$ & $16.6 \mathrm{bps}$ & $14.1 \mathrm{bps}$ & $14.7 \mathrm{bps}$ & $31.7 \mathrm{bps}$ & $24.7 \mathrm{bps}$ & $25.1 \mathrm{bps}$ \\
\hline $\begin{array}{l}\text { correlation } \\
\text { parameters }\end{array}$ & $\begin{array}{c}0.0246 \\
(0.0016) \\
\rho_{1}^{S h o r t, L o n g} \\
0.304 \\
(0.0579)\end{array}$ & $\begin{array}{c}0.0222 \\
(0.0015) \\
\rho_{1}^{\text {Short }, \text { Med }} \text {. } \\
0.669 \\
(0.0359) \\
\end{array}$ & $\begin{array}{c}0.0207 \\
(0.0014) \\
\rho_{1}^{M e d ., L o n g} \\
0.7139 \\
(0.0319)\end{array}$ & $\begin{array}{c}0.0724 \\
(0.0053) \\
\rho_{2}^{\text {Short }, \text { Long }} \\
0.252 \\
(0.0679)\end{array}$ & $\begin{array}{c}0.0585 \\
(0.0036) \\
\rho_{2}^{S h o r t, M e d .} \\
0.4439 \\
(0.0666) \\
\end{array}$ & $\begin{array}{c}0.0502 \\
(0.003) \\
\rho_{2}^{\text {Med.,Long }} \\
0.7626 \\
(0.0299)\end{array}$ \\
\hline $\begin{array}{l}\text { transition } \\
\text { probabilities }\end{array}$ & \multicolumn{3}{|c|}{$\begin{array}{c}p_{1,1} \\
0.9056 \\
(0.0207)\end{array}$} & \multicolumn{3}{|c|}{$\begin{array}{c}p_{2,2} \\
0.8392 \\
(0.0347) \\
\end{array}$} \\
\hline Constant & $\begin{array}{c}0.0082 \\
(0.0089)\end{array}$ & $\begin{array}{c}0.0063 \\
(0.0087)\end{array}$ & $\begin{array}{c}0.0079 \\
(0.009)\end{array}$ & $\begin{array}{c}-0.0139 \\
(0.0217)\end{array}$ & $\begin{array}{c}0.0017 \\
(0.0221)\end{array}$ & $\begin{array}{c}0.0049 \\
(0.0293)\end{array}$ \\
\hline$i l l i q_{t-1}(T)$ & $\begin{array}{l}0.5789^{* *} \\
(0.0568)\end{array}$ & $\begin{array}{l}0.6821^{* *} \\
(0.0503)\end{array}$ & $\begin{array}{l}0.7064^{* *} \\
(0.0564)\end{array}$ & $\begin{array}{l}0.5635^{* *} \\
(0.0726)\end{array}$ & $\begin{array}{l}0.4955^{* *} \\
(0.0705)\end{array}$ & $\begin{array}{c}0.5147^{* *} \\
(0.0645)\end{array}$ \\
\hline$i l l i q_{t-2}(T)$ & $\begin{array}{l}0.1782^{* *} \\
(0.0542)\end{array}$ & $\begin{array}{r}0.164^{* *} \\
(0.0469)\end{array}$ & $\begin{array}{l}0.2457^{* *} \\
(0.0614)\end{array}$ & $\begin{array}{r}0.1762^{*} \\
(0.0753)\end{array}$ & $\begin{array}{c}0.1032 \\
(0.067)\end{array}$ & $\begin{array}{c}0.131 \\
(0.0725)\end{array}$ \\
\hline$i l l i q_{t-3}(T)$ & $\begin{array}{l}0.1717^{* *} \\
(0.0413)\end{array}$ & $\begin{array}{l}0.1164^{* *} \\
(0.0338)\end{array}$ & $\begin{array}{c}0.0117 \\
(0.0516)\end{array}$ & $\begin{array}{c}0.0102 \\
(0.0733)\end{array}$ & $\begin{array}{c}0.1212 \\
(0.0657)\end{array}$ & $\begin{array}{r}0.1623^{*} \\
(0.0739)\end{array}$ \\
\hline $\operatorname{invRisk}_{t}(T)$ & $\begin{array}{c}0.0005 \\
(0.0003)\end{array}$ & $\begin{array}{c}0.0000 \\
(0.0007)\end{array}$ & $\begin{array}{c}0.0000 \\
(0.0008)\end{array}$ & $\begin{array}{c}0.003^{* *} \\
(0.0008)\end{array}$ & $\begin{array}{l}0.0027^{* *} \\
(0.0009)\end{array}$ & $\begin{array}{l}0.003^{* *} \\
(0.001)\end{array}$ \\
\hline $\operatorname{trblVol} t(T)$ & $\begin{array}{c}-0.0101 \\
(0.0166)\end{array}$ & $\begin{array}{c}0.0057 \\
(0.0213)\end{array}$ & $\begin{array}{c}-0.0028 \\
(0.0304)\end{array}$ & $\begin{array}{c}-0.0799 \\
(0.0561)\end{array}$ & $\begin{array}{c}-0.1708^{* *} \\
(0.0564)\end{array}$ & $\begin{array}{c}-0.0292 \\
(0.0915)\end{array}$ \\
\hline $\operatorname{DivYldDax} x_{t}$ & $\begin{array}{c}0.0031 \\
(0.0041)\end{array}$ & $\begin{array}{c}-0.0014 \\
(0.004)\end{array}$ & $\begin{array}{c}-0.0014 \\
(0.0041)\end{array}$ & $\begin{array}{l}0.0336^{* *} \\
(0.0105)\end{array}$ & $\begin{array}{l}0.0332^{* *} \\
(0.0114)\end{array}$ & $\begin{array}{c}0.0153 \\
(0.0102)\end{array}$ \\
\hline & \multicolumn{2}{|c|}{$\begin{array}{c}\text { Log-Likelihood } \\
4529.64\end{array}$} & $\begin{array}{c}\mathrm{N} \\
700\end{array}$ & $\begin{array}{c}\text { AIC } \\
-8947.28\end{array}$ & $\begin{array}{c}\text { BIC } \\
-8630.9\end{array}$ & \\
\hline
\end{tabular}


Table XIII: Robustness Check: Dynamic Linkages

This table shows the results of the maximum likelihood estimation of Model (12), (13), (14), (7), and (8) with $p=3$ and $q=1$. White's (1982) standard errors are given in parentheses. *,** indicate significance at the $5 \%$ or $1 \%$ level. The observation period is May 7th, 1997 to September 29th, 2010.

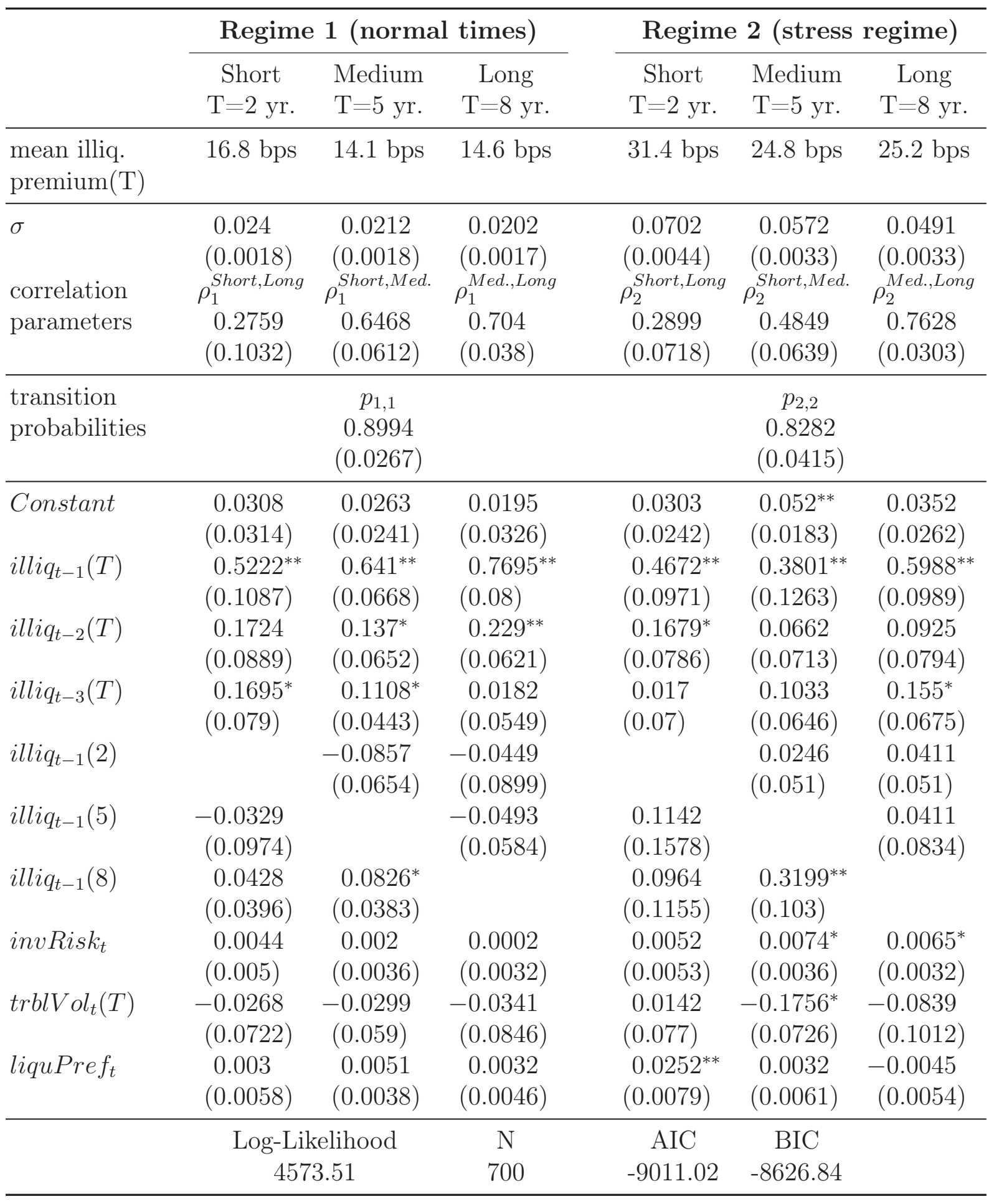


Table XIV: Robustness Check: Bid-Ask Spread and Separation of Liquidity Preferences and Inventory Risk

This table shows the results of the maximum likelihood estimation of Model (9), (10), (11), (7), and (8) with $p=3$ with BidAskDifr $r_{t}(T)$ instead of liquPref $f_{t}$ and $\operatorname{trblVol}_{t}(T)$. BidAskDifr $_{t}(T)$ refers to quoted relative bid-ask spread differences between KfW bonds and BUNDs (see also Figure 2). liquPref IntVol substitutes liquPref $_{t}$ in (9)-(11) and is the first principal component of the VDAX New, the TED spread, the dividend yield of the DAX, and the five year swaption volatility orthogonalized with the three months Euribor (data from Bloomberg). White's (1982) standard errors are given in parentheses. *, ** indicate significance at the $5 \%$ or $1 \%$ level. The observation period is August 22nd, 2001 to September 30th, 2010.

\begin{tabular}{|c|c|c|c|c|c|c|}
\hline & \multicolumn{3}{|c|}{ Regime 1 (normal times) } & \multicolumn{3}{|c|}{ Regime 2 (stress regime) } \\
\hline & $\begin{array}{c}\text { Short } \\
\mathrm{T}=2 \mathrm{yr} .\end{array}$ & $\begin{array}{l}\text { Medium } \\
\mathrm{T}=5 \mathrm{yr} .\end{array}$ & $\begin{array}{c}\text { Long } \\
\mathrm{T}=8 \mathrm{yr} .\end{array}$ & $\begin{array}{c}\text { Short } \\
\mathrm{T}=2 \mathrm{yr} .\end{array}$ & $\begin{array}{l}\text { Medium } \\
\mathrm{T}=5 \mathrm{yr} .\end{array}$ & $\begin{array}{c}\text { Long } \\
\mathrm{T}=8 \mathrm{yr} .\end{array}$ \\
\hline $\begin{array}{l}\text { mean illiq. } \\
\text { premium(T) }\end{array}$ & $15.7 \mathrm{bps}$ & $9.9 \mathrm{bps}$ & $10.6 \mathrm{bps}$ & $32.9 \mathrm{bps}$ & $25.1 \mathrm{bps}$ & $25.4 \mathrm{bps}$ \\
\hline $\begin{array}{l}\text { correlation } \\
\text { parameters }\end{array}$ & $\begin{array}{c}0.0215 \\
(0.002) \\
\rho_{1}^{\text {Short }, \text { Long }} \\
0.135 \\
(0.0956)\end{array}$ & $\begin{array}{c}0.0168 \\
(0.001) \\
\rho_{1}^{\text {Short }, \text { Med. }} \\
0.5987 \\
(0.0622)\end{array}$ & $\begin{array}{c}0.0128 \\
(0.0008) \\
\rho_{1}^{\text {Med.,Long }} \\
0.6184 \\
(0.0551)\end{array}$ & $\begin{array}{c}0.0702 \\
(0.0039) \\
\rho_{2}^{\text {Short }, \text { Long }} \\
0.2901 \\
(0.0706)\end{array}$ & $\begin{array}{c}0.0576 \\
(0.0033) \\
\rho_{2}^{\text {Short }, \text { Med. }} \\
0.4729 \\
(0.063)\end{array}$ & $\begin{array}{c}0.0464 \\
(0.003) \\
\rho_{2}^{\text {Med.,Long }} \\
0.7621 \\
(0.0309)\end{array}$ \\
\hline $\begin{array}{l}\text { transition } \\
\text { probabilities }\end{array}$ & & $\begin{array}{c}p_{1,1} \\
0.8435 \\
(0.0336)\end{array}$ & & & $\begin{array}{c}p_{2,2} \\
0.8667 \\
(0.0301)\end{array}$ & \\
\hline Constant & $\begin{array}{l}0.0247^{* *} \\
(0.0057)\end{array}$ & $\begin{array}{l}0.0121^{* *} \\
(0.0033)\end{array}$ & $\begin{array}{l}0.0178^{* *} \\
(0.0037)\end{array}$ & $\begin{array}{c}0.0338^{* *} \\
(0.0095)\end{array}$ & $\begin{array}{c}0.0222^{* *} \\
(0.0071)\end{array}$ & $\begin{array}{l}0.0245^{* *} \\
(0.0054)\end{array}$ \\
\hline$i_{l l i q_{t-1}}(T)$ & $\begin{array}{r}0.567^{* *} \\
(0.0826)\end{array}$ & $\begin{array}{c}0.6179^{* *} \\
(0.0477)\end{array}$ & $\begin{array}{c}0.4348^{* *} \\
(0.0751)\end{array}$ & $\begin{array}{c}0.5006^{* *} \\
(0.0724)\end{array}$ & $\begin{array}{c}0.4778^{* *} \\
(0.0678)\end{array}$ & $\begin{array}{c}0.5048^{* *} \\
(0.0625)\end{array}$ \\
\hline$i l l i q_{t-2}(T)$ & $\begin{array}{c}0.1102^{*} \\
(0.0461)\end{array}$ & $\begin{array}{c}0.1107^{* *} \\
(0.0361)\end{array}$ & $\begin{array}{c}0.2555^{* *} \\
(0.0496)\end{array}$ & $\begin{array}{c}0.1939^{* *} \\
(0.0716)\end{array}$ & $\begin{array}{r}0.1297 \\
(0.069)\end{array}$ & $\begin{array}{r}0.1545^{*} \\
(0.0764)\end{array}$ \\
\hline$i l l i q_{t-3}(T)$ & $\begin{array}{c}0.115^{*} \\
(0.0586)\end{array}$ & $\begin{array}{c}0.1462^{* *} \\
(0.0489)\end{array}$ & $\begin{array}{c}0.1412 \\
(0.0722)\end{array}$ & $\begin{array}{c}0.0361 \\
(0.0711)\end{array}$ & $\begin{array}{c}0.1089 \\
(0.0662)\end{array}$ & $\begin{array}{c}0.1273 \\
(0.0677)\end{array}$ \\
\hline $\operatorname{BidAskDifr}_{t}(T)$ & $\begin{array}{c}0.1216 \\
(0.0626)\end{array}$ & $\begin{array}{c}-0.0127 \\
(0.0355)\end{array}$ & $\begin{array}{c}-0.0179 \\
(0.0277)\end{array}$ & $\begin{array}{r}0.1585^{*} \\
(0.0683)\end{array}$ & $\begin{array}{l}0.1654^{* *} \\
(0.0431)\end{array}$ & $\begin{array}{l}0.0905^{* *} \\
(0.033)\end{array}$ \\
\hline liquPref IntVol ${ }_{t}$ & $\begin{array}{l}0.0065^{* *} \\
(0.0024)\end{array}$ & $\begin{array}{c}0.0036^{*} \\
(0.0017)\end{array}$ & $\begin{array}{r}0.0045^{*} \\
(0.0019)\end{array}$ & $\begin{array}{c}0.0289^{* *} \\
(0.0055)\end{array}$ & $\begin{array}{c}0.0164^{* *} \\
(0.0037)\end{array}$ & $\begin{array}{l}0.0114^{* *} \\
(0.003)\end{array}$ \\
\hline & $\begin{array}{r}\text { Log-Lil } \\
299\end{array}$ & $\begin{array}{l}\text { zelihood } \\
6.55\end{array}$ & $\begin{array}{c}\mathrm{N} \\
476\end{array}$ & $\begin{array}{c}\text { AIC } \\
-5893.09\end{array}$ & $\begin{array}{c}\mathrm{BIC} \\
-5629.89\end{array}$ & \\
\hline
\end{tabular}


Table XV: Robustness Check: Monthly Analysis

This table shows the results of the maximum likelihood estimation of Model (9), (10), (11), (7), and (8) with $p=3$. White's (1982) standard errors are given in parentheses. *, ** indicate significance at the $5 \%$ or $1 \%$ level. The observation period is May 31th, 1997 to September 30th, 2010.

\begin{tabular}{|c|c|c|c|c|c|c|}
\hline & \multicolumn{3}{|c|}{ Regime 1 (normal times) } & \multicolumn{3}{|c|}{ Regime 2 (stress regime) } \\
\hline & $\begin{array}{c}\text { Short } \\
\mathrm{T}=2 \mathrm{yr} .\end{array}$ & $\begin{array}{l}\text { Medium } \\
\mathrm{T}=5 \mathrm{yr} .\end{array}$ & $\begin{array}{c}\text { Long } \\
\mathrm{T}=8 \mathrm{yr} .\end{array}$ & $\begin{array}{c}\text { Short } \\
\mathrm{T}=2 \mathrm{yr} .\end{array}$ & $\begin{array}{l}\text { Medium } \\
\mathrm{T}=5 \mathrm{yr} .\end{array}$ & $\begin{array}{c}\text { Long } \\
\mathrm{T}=8 \mathrm{yr} .\end{array}$ \\
\hline $\begin{array}{l}\text { mean illiq. } \\
\operatorname{premium}(\mathrm{T})\end{array}$ & $13.2 \mathrm{bps}$ & $10.5 \mathrm{bps}$ & $10.4 \mathrm{bps}$ & $41.0 \mathrm{bps}$ & $34.6 \mathrm{bps}$ & $36.0 \mathrm{bps}$ \\
\hline $\begin{array}{l}\text { correlation } \\
\text { parameters }\end{array}$ & $\begin{array}{c}0.031 \\
(0.003) \\
\rho_{1}^{\text {Short,Long }} \\
-0.1192 \\
(0.1113)\end{array}$ & $\begin{array}{c}0.0297 \\
(0.0023) \\
\rho_{1}^{S h o r t, M e d} . \\
0.0324 \\
(0.1506)\end{array}$ & $\begin{array}{c}0.0311 \\
(0.0025) \\
\rho_{1}^{M e d ., \text { Long }} \\
0.5049 \\
(0.0898)\end{array}$ & $\begin{array}{c}0.0755 \\
(0.0096) \\
\rho_{2}^{\text {Short }, \text { Long }} \\
0.1708 \\
(0.2346)\end{array}$ & $\begin{array}{c}0.0671 \\
(0.0063) \\
\rho_{2}^{\text {Short }, \text { Med. }} \\
0.4538 \\
(0.1694)\end{array}$ & $\begin{array}{c}0.0641 \\
(0.0063) \\
\rho_{2}^{\text {Med.,Long }} \\
0.8916 \\
(0.0307)\end{array}$ \\
\hline $\begin{array}{l}\text { transition } \\
\text { probabilities }\end{array}$ & \multicolumn{3}{|c|}{$\begin{array}{c}p_{1,1} \\
0.9600 \\
(0.0189)\end{array}$} & \multicolumn{3}{|c|}{$\begin{array}{c}p_{2,2} \\
0.9350 \\
(0.0489)\end{array}$} \\
\hline Constant & $\begin{array}{c}0.1242^{* *} \\
(0.0468)\end{array}$ & $\begin{array}{c}0.0267 \\
(0.0202)\end{array}$ & $\begin{array}{c}0.0203 \\
(0.0265)\end{array}$ & $\begin{array}{c}0.141^{* *} \\
(0.0323)\end{array}$ & $\begin{array}{c}0.2786^{* *} \\
(0.0539)\end{array}$ & $\begin{array}{c}0.2786^{* *} \\
(0.0425)\end{array}$ \\
\hline$i_{l l i q} q_{t-1}(T)$ & $\begin{array}{l}0.4358^{* *} \\
(0.095)\end{array}$ & $\begin{array}{l}0.4335^{* *} \\
(0.0845)\end{array}$ & $\begin{array}{l}0.4358^{* *} \\
(0.0953)\end{array}$ & $\begin{array}{c}0.5695^{* *} \\
(0.0905)\end{array}$ & $\begin{array}{c}0.397^{* *} \\
(0.1118)\end{array}$ & $\begin{array}{c}0.4736^{* *} \\
(0.1224)\end{array}$ \\
\hline$i l l i q_{t-2}(T)$ & $\begin{array}{c}-0.1319 \\
(0.1487)\end{array}$ & $\begin{array}{c}0.1672 \\
(0.0995)\end{array}$ & $\begin{array}{c}0.0355 \\
(0.0859)\end{array}$ & $\begin{array}{c}-0.3715^{* *} \\
(0.1099)\end{array}$ & $\begin{array}{c}-0.0642 \\
(0.087)\end{array}$ & $\begin{array}{c}-0.0917 \\
(0.1158)\end{array}$ \\
\hline$i l l i q_{t-3}(T)$ & $\begin{array}{c}0.1397 \\
(0.1199)\end{array}$ & $\begin{array}{l}0.1873^{* *} \\
(0.0722)\end{array}$ & $\begin{array}{c}0.2652^{* *} \\
(0.0744)\end{array}$ & $\begin{array}{c}0.2041^{* *} \\
(0.0644)\end{array}$ & $\begin{array}{c}0.1844^{*} \\
(0.0793)\end{array}$ & $\begin{array}{c}0.1857^{*} \\
(0.0834)\end{array}$ \\
\hline invRisk $_{t}$ & $\begin{array}{c}0.014^{*} \\
(0.0066)\end{array}$ & $\begin{array}{c}-0.0012 \\
(0.0042)\end{array}$ & $\begin{array}{c}-0.0013 \\
(0.0036)\end{array}$ & $\begin{array}{r}0.0122^{*} \\
(0.0061)\end{array}$ & $\begin{array}{c}0.015^{* *} \\
(0.0056)\end{array}$ & $\begin{array}{c}0.0148^{*} \\
(0.0059)\end{array}$ \\
\hline $\operatorname{trblVol}_{t}(T)$ & $\begin{array}{l}-0.163 \\
(0.0837)\end{array}$ & $\begin{array}{c}-0.0226 \\
(0.0685)\end{array}$ & $\begin{array}{c}0.0271 \\
(0.1137)\end{array}$ & $\begin{array}{c}0.0711 \\
(0.1836)\end{array}$ & $\begin{array}{c}-0.7903^{* *} \\
(0.2732)\end{array}$ & $\begin{array}{c}-0.6082^{* *} \\
(0.1145)\end{array}$ \\
\hline liquPref $f_{t}$ & $\begin{array}{c}0.0022 \\
(0.0069)\end{array}$ & $\begin{array}{c}0.0088 \\
(0.0053)\end{array}$ & $\begin{array}{c}0.0093 \\
(0.0056)\end{array}$ & $\begin{array}{l}0.0752^{* *} \\
(0.0181)\end{array}$ & $\begin{array}{l}0.0313^{* *} \\
(0.0103)\end{array}$ & $\begin{array}{c}0.0202 \\
(0.0129)\end{array}$ \\
\hline & \multicolumn{2}{|c|}{$\begin{array}{c}\text { Log-Likelihood } \\
921.36\end{array}$} & $\begin{array}{c}\mathrm{N} \\
161\end{array}$ & $\begin{array}{c}\text { AIC } \\
-1730.72\end{array}$ & $\begin{array}{c}\text { BIC } \\
-1496.64\end{array}$ & \\
\hline
\end{tabular}


Table XVI: Robustness Check: Exogenous Crises Specification

This table shows the results of the estimation of Model (9) - (11) with exogenously specified stress periods (LTCM-crisis: June, 1st to October 31st, 1998; burst of dot-com bubble: May 10th, 2001 to June 30th, 2003; financial and subsequent European debt crisis: June 1st, 2007 to September 29th, 2010). Newey and West's (1987) standard errors with five lags are given in parentheses. $*$, ** indicate significance at the $5 \%$ or $1 \%$ level. The total observation period is May 7th, 1997 to September 29th, 2010.

\begin{tabular}{|c|c|c|c|c|c|c|}
\hline & \multicolumn{3}{|c|}{ Non Crisis } & \multicolumn{3}{|c|}{ Crisis } \\
\hline & $\begin{array}{c}\text { Short } \\
\mathrm{T}=2 \mathrm{yr} .\end{array}$ & $\begin{array}{l}\text { Medium } \\
\mathrm{T}=5 \mathrm{yr} .\end{array}$ & $\begin{array}{c}\text { Long } \\
\mathrm{T}=8 \mathrm{yr} .\end{array}$ & $\begin{array}{c}\text { Short } \\
\mathrm{T}=2 \mathrm{yr} .\end{array}$ & $\begin{array}{l}\text { Medium } \\
\mathrm{T}=5 \mathrm{yr} .\end{array}$ & $\begin{array}{l}\text { Long } \\
\mathrm{T}=8 \mathrm{yr} .\end{array}$ \\
\hline $\begin{array}{l}\text { mean illiq. } \\
\operatorname{premium}(\mathrm{T})\end{array}$ & $14.1 \mathrm{bps}$ & $12.0 \mathrm{bps}$ & $12.8 \mathrm{bps}$ & $32.6 \mathrm{bps}$ & $25.7 \mathrm{bps}$ & $25.9 \mathrm{bps}$ \\
\hline Constant & $\begin{array}{c}0.0816^{* *} \\
(0.0125)\end{array}$ & $\begin{array}{c}0.0165 \\
(0.0098)\end{array}$ & $\begin{array}{c}0.0141 \\
(0.0115)\end{array}$ & $\begin{array}{l}0.0633^{* *} \\
(0.016)\end{array}$ & $\begin{array}{c}0.046^{* *} \\
(0.014)\end{array}$ & $\begin{array}{c}-0.0055 \\
(0.0253)\end{array}$ \\
\hline$i l l i q_{t-1}(T)$ & $\begin{array}{c}0.2999^{* *} \\
(0.0695)\end{array}$ & $\begin{array}{c}0.7208^{* *} \\
(0.0555)\end{array}$ & $\begin{array}{c}0.6863^{* *} \\
(0.0834)\end{array}$ & $\begin{array}{c}0.5861^{* *} \\
(0.0678)\end{array}$ & $\begin{array}{c}0.6742^{* *} \\
(0.0675)\end{array}$ & $\begin{array}{c}0.7333^{* *} \\
(0.0585)\end{array}$ \\
\hline$i l l i q_{t-2}(T)$ & $\begin{array}{l}0.1404^{* *} \\
(0.0508)\end{array}$ & $\begin{array}{c}-0.0102 \\
(0.1104)\end{array}$ & $\begin{array}{l}0.1399 \\
(0.08)\end{array}$ & $\begin{array}{l}0.2208^{* *} \\
(0.0814)\end{array}$ & $\begin{array}{r}0.1792^{*} \\
(0.0797)\end{array}$ & $\begin{array}{c}0.2246^{*} \\
(0.0901)\end{array}$ \\
\hline$i l l i q_{t-3}(T)$ & $\begin{array}{l}0.1846^{* *} \\
(0.0555)\end{array}$ & $\begin{array}{r}0.2275^{*} \\
(0.1021)\end{array}$ & $\begin{array}{c}0.1429 \\
(0.0839)\end{array}$ & $\begin{array}{c}0.0218 \\
(0.0789)\end{array}$ & $\begin{array}{c}0.0275 \\
(0.0538)\end{array}$ & $\begin{array}{r}-0.0654 \\
(0.0723)\end{array}$ \\
\hline invRisk $_{t}$ & $\begin{array}{l}0.0088^{* *} \\
(0.0021)\end{array}$ & $\begin{array}{c}0.0025 \\
(0.0023)\end{array}$ & $\begin{array}{c}0.0017 \\
(0.0013)\end{array}$ & $\begin{array}{c}0.0059^{*} \\
(0.0025)\end{array}$ & $\begin{array}{c}0.0061^{* *} \\
(0.0016)\end{array}$ & $\begin{array}{r}0.0038^{*} \\
(0.0019)\end{array}$ \\
\hline $\operatorname{trblVol}_{t}(T)$ & $\begin{array}{c}-0.0782^{* *} \\
(0.0295)\end{array}$ & $\begin{array}{r}-0.0164 \\
(0.0368)\end{array}$ & $\begin{array}{r}-0.0318 \\
(0.0542)\end{array}$ & $\begin{array}{c}-0.1319^{* *} \\
(0.0485)\end{array}$ & $\begin{array}{r}-0.1196^{*} \\
(0.0527)\end{array}$ & $\begin{array}{c}0.0939 \\
(0.1046)\end{array}$ \\
\hline liquPref $f_{t}$ & $\begin{array}{l}0.005 \\
(0.0041)\end{array}$ & $\begin{array}{c}0.0042 \\
(0.0036)\end{array}$ & $\begin{array}{c}0.0018 \\
(0.0035)\end{array}$ & $\begin{array}{l}0.0183^{* *} \\
(0.0064)\end{array}$ & $\begin{array}{c}0.0033 \\
(0.0043)\end{array}$ & $\begin{array}{l}0.004 \\
(0.0039)\end{array}$ \\
\hline adj. $R^{2}$ & 0.579 & 0.9035 & 0.9463 & 0.9466 & 0.9332 & 0.9453 \\
\hline
\end{tabular}




\section{Working Paper Series in Economics}

recent issues

No. 45 Philipp Schuster and Marliese Uhrig-Homburg: The term structure of bond market liquidity conditional on the economic environment: an analysis of government guaranteed bonds, November 2012

No. 44 Young Shin Kim, Rosella Giacometti, Svetlozar T. Rachev, Frank J. Fabozzi, Domenico Mignacca: Measuring financial risk and portfolio optimization with a non-Gaussian multivariate model, August 2012

No. 43 Zuodong Lin, Svetlozar T. Rachev, Young Shin Kim, Frank J. Fabozzi: Option pricing with regime switching tempered stable processes, August 2012

No. 42 Siegfried K. Berninghaus, Werner Güth, Stephan Schosser: Backward induction or forward reasoning? An experiment of stochastic alternating offer bargaining, July 2012

No. 41 Siegfried Berninghaus, Werner Güth, King King Li: Approximate truth of perfectness - an experimental test, June 2012

No. 40 Marten Hillebrand and Tomoo Kikuchi: A mechanism for booms and busts in housing prices, May 2012

No. 39 Antje Schimke: Entrepreneurial aging and employment growth in the context of extreme growth events, May 2012

No. 38 Antje Schimke, Nina Teichert, Ingrid Ott: Impact of local knowledge endowment on employment growth in nanotechnology, February 2012

No. 37 Siegfried K. Berninghaus, Lora Todorova, Bodo Vogt: A simple questionnaire can change everything - are strategy choices in coordination games stable?, December 2011

No. 36 Matthias Duschl, Antje Schimke, Thomas Brenner, Dennis Luxen: Firm growth and the spatial impact of geolocated external factors - empirical evidence for German manufacturing firms, November 2011 